\title{
EVOLUTION OF ADAPTIVE PLASTICITY: RISK-SENSITIVE HATCHING IN NEOTROPICAL LEAF-BREEDING TREEFROGS
}

\author{
Ivan Gomez-Mestre, ${ }^{1,3}$ John J. Wiens, ${ }^{2}$ And Karen M. Warkentin ${ }^{1}$ \\ ${ }^{1}$ Department of Biology, Boston University, 5 Cummington Street, Boston, Massachusetts 02215 USA \\ ${ }^{2}$ Department of Ecology and Evolution, Stony Brook University, Stony Brook, New York 11794-5245 USA
}

Abstract. Adaptive plasticity at switch points in complex life cycles (e.g., hatching, metamorphosis) is well known, but the evolutionary history of such plasticity is not. Particularly unclear is how a single plastic response (e.g., shifts in hatching timing) evolves to respond to different threats and cues (e.g., abiotic and biotic). We conducted a comparative phylogenetic study of hatching plasticity in a group of frogs with arboreal embryos to determine when risk-accelerated hatching evolved in the clade, whether responses to two common egg-stage risks (snake predation and flooding) evolved independently, and whether the overall capacity for hatching plasticity was evolutionarily more conservative than responses to specific cues. Red-eyed treefrogs (Agalychnis callidryas) hatch early to escape from several egg-stage risks but otherwise hatch later, improving larval survival with predators. We reconstructed a phylogeny for Agalychnis and related genera based on three mitochondrial and four nuclear genes. We quantified onset of hatching competence, spontaneous hatching timing, responses to egg-stage risks, and costs of premature hatching in Agalychnis and Pachymedusa. We also assessed hatching plasticity in a basal phyllomedusine, Cruziohyla calcarifer. The capacity to hatch $\sim 30 \%$ before the spontaneous hatching age appears ancestral for phyllomedusines, with little change over $\sim 34-50$ million years among the species examined. A strong hatching response to flooding, with no mortality of hatching-competent eggs, is similarly ancient and conserved. Premature hatchlings of Agalychnis and Pachymedusa are more vulnerable to fish predation than are full-term hatchlings, indicating a conserved risk trade-off across hatching that would make plasticity advantageous. In contrast, the hatching response to snake attack has undergone major changes at least twice in the Agalychnis-Pachymedusa clade, with two species showing substantially lower escape success than the others. Responses to different threats have thus evolved independently. The capacity for switch point plasticity may be evolutionarily more stable than the response to individual stage-specific threats.

Key words: Agalychnis; amphibian; antipredator behavior; embryo behavior; hypoxic stress; inducible defense; life-history switch point; ontogenetic niche shift; Pachymedusa; phenotypic plasticity; phylogeny; predation.

\section{INTRODUCTION}

Adaptive phenotypic plasticity is the ability of genetically similar organisms to express appropriately different phenotypes in different selective environments. Although sometimes treated as a single trait, adaptive plasticity typically depends on a multicomponent developmental or regulatory pathway, which includes sensors that detect environmental conditions and mechanisms that alter the phenotype accordingly (Tollrian and Harvell 1998, West-Eberhard 2003, DeWitt and Scheiner 2004). A rich body of empirical research has documented the ecological importance of adaptive plasticity in diverse taxa, but to date there are few

Manuscript received 30 March 2007; revised 9 August 2007; accepted 21 August 2007. Corresponding Editor: J. Van Buskirk (Ecological Applications Board of Editors).

${ }^{3}$ Present address: Estación Biológica de Doñana, Consejo Superior de Investigaciones Científicas, Avda. Maria Luisa s/n, Pabellón de Perú, Sevilla E41013 Spain.

E-mail: igmestre@ebd.csic.es phylogenetic studies of its evolution (but see Roskam and Brakefield 1996, Colbourne et al. 1997, Pigliucci et al. 1999, Van Buskirk 2002, Kembel and Cahill 2005, Schmidt and Van Buskirk 2005, Gomez-Mestre and Buchholz 2006). Comparative phylogenetic studies of plasticity in an ecological context can clarify the frequency, direction, and sequence of evolutionary changes in plastic traits and how they coevolve with other traits (Doughty 1995, Pigliucci et al. 1999).

Comparative studies may also clarify the evolutionary relationships between different components of plasticity. Many organisms show a similar plastic response to multiple environmental factors, with this response mediated by different environmental cues (e.g., tadpoles can accelerate metamorphosis in response to both larval predators and pond drying [Newman 1992, Benard 2004]; waterfleas can tune the extent of diel migration in the water column in response to light, predators, and food availability [Van Gool and Ringelberg 1998]). Because of the paucity of comparative studies of plastic 
responses to different factors, it is unclear whether the capacity to express a particular range of phenotypes predates the coupling of plastic responses to currently used cues. For instance, variation in one environmental factor could initially select for a plastic response, and the range of phenotypes expressed could expand in this context. Later, a mechanism could evolve that couples this preexisting phenotypic response to a new environmental cue. Alternatively, variation in multiple selective factors could act together to favor the evolution of plasticity in a given trait, so that responses to different cues evolve concurrently. These hypotheses are best tested in the context of a phylogenetic comparative analysis, by mapping the phylogenetic distribution of overall trait plasticity and phenotypic responses to different cues. This approach may reveal the original selective factors favoring the evolution of plasticity and the historical sequence in which phenotypic responses to different cues have evolved. We apply this approach to the study of adaptive plasticity in the timing of an ontogenetic switch point.

Most animal species have complex life cycles, consisting of a series of ecologically and often morphologically distinct stages (Werner 1988, Hall and Wake 1999). These life stages are often exposed to different selective factors, so that the timing of transitions between stages (ontogenetic switch points) can substantially affect fitness (Wilbur and Collins 1973, Werner and Gilliam 1984). If environmental quality varies in one or both adjacent life stages across a switch point, a single fixed switch time cannot consistently maximize fitness. Such environmental heterogeneity will therefore selectively favor switch point plasticity (Werner 1986, 1988, Rowe and Ludwig 1991). Hatching is the first ontogenetic switch point in the lives of most animals. Hatchlings leave the protection and constraints of the egg, gaining mobility and access to external resources. Both eggs and newly hatched young often suffer high levels of mortality (Wilbur 1980, Gosselin and Qian 1997), creating a strong opportunity for natural selection (Arnold 1986). Hatching plasticity may occur in response to physical conditions, predators, and/or pathogens and is found in a variety of vertebrate and invertebrate taxa (reviewed in Martin 1999, Warkentin 2007).

Here we present a phylogenetic comparative study of adaptive plasticity in the timing of hatching in a group of Neotropical leaf-breeding treefrogs (genus Agalychnis, along with the closely related Pachymedusa dacnicolor and the more distantly related Cruziohyla calcarifer). Risk-induced premature hatching is a key defensive mechanism that allows embryos to escape from egg-stage risks (Gomez-Mestre et al. 2006, Warkentin et al. 2007). We focus on the evolution of premature hatching in response to two common eggstage risks: snake predation and flooding. Hatching plasticity in response to flooding has long been known in species with anamniote terrestrial eggs and aquatic larvae (reviewed in Martin 1999). Hatching plasticity in response to egg and/or larval predators and pathogens is a more recent discovery (Sih and Moore 1993, Warkentin 1995). We now know that a variety of amphibian species, and a few fish and reptile species, show adaptive shifts in hatching timing in response to biotic risks (Chivers et al. 2001, Laurila et al. 2002, Wedekind 2002, Saenz et al. 2003, Kusch and Chivers 2004, Moreira and Barata 2005, Vonesh 2005, GomezMestre et al. 2006).

The red-eyed treefrog, Agalychnis callidryas, offers a well-studied case of adaptive plasticity in hatching timing. This species lays eggs on vegetation over ponds, and its tadpoles fall into the water upon hatching (Warkentin 1995, Duellman 2001). The embryos can hatch prematurely and escape in response to predator attacks (snakes and wasps; Warkentin 1995, 2000b), pathogenic fungus infection (Warkentin et al. 2001), and underwater submergence (which kills less-developed eggs; Pyburn 1970, Warkentin 2002). Vibrations cue hatching during snake attacks, whereas hypoxic stress stimulates hatching of submerged clutches (Warkentin 2002, 2005). These risks occur at different frequencies, with snake predation substantially more common than underwater submergence in nature (Warkentin 1995, 2000b, Gomez-Mestre and Warkentin 2007). Eggs of all other Agalychnis species, Cruziohyla calcarifer, and Pachymedusa dacnicolor are also laid on vegetation over water and co-occur with various species of egg-eating snakes (Duellman 2001). Some clutches are laid close enough to the water surface that natural fluctuations of water level flood clutches, killing eggs too young to hatch (Pyburn 1970, Warkentin 2000b, Gomez-Mestre and Warkentin 2007). Also, these species often co-occur with small fishes and other aquatic predators of tadpoles. Thus the egg- and larval-stage risks (flooding, snake predation, and fish predation) studied here are ecologically relevant, naturally variable risks for these frog species.

Studying trait evolution among species requires a phylogenetic context. Prior phylogenies of Agalychnis that included all species were based on morphological characters and yielded poorly resolved trees (Cruz 1990, Duellman 2001). Conversely, previous molecular phylogenies did not include all Agalychnis species (Faivovich et al. 2005, Wiens et al. 2005, 2006). We therefore collected new DNA sequence data to resolve the phylogenetic relationships among all Agalychnis species.

Combining the phylogeny and comparative data on hatching-related traits, we addressed the following questions: (1) Is risk-induced hatching ancestral in this clade or has it evolved more recently? (2) How phylogenetically widespread are the survival trade-offs between stage-specific risks that make hatching plasticity adaptive? (3) Have embryo responses to risks remained stable over long periods of time or changed among closely related species? (4) Have responses to different risks evolved concurrently or independently? (5) Are 
responses to different types of risk equally evolutionarily labile? (6) Is the capacity for hatching acceleration evolutionarily more conservative than its expression in response to specific types of cues? (7) Are evolutionary changes across species in embryo responses to risk associated with changes in other reproductive or egg traits?

\section{Materials And Methods}

\section{Study species and sites}

We used a combination of field observations and experiments with six species of Agalychnis and Pachymedusa in order to determine their undisturbed hatching patterns and onset of hatching competence, assess responses to two different egg-stage risks (flooding, snake attacks), and test for a cost of early hatching. We also assessed egg clutch thickness, which is a key structural attribute affecting vibration mechanics. Vibrations are important cues in snake predation (Warkentin 2005). Finally, we considered breeding phenology as a trait potentially related to risk of egg predation, because high reproductive synchrony can decrease predation risk via predator swamping (Ims 1990).

Agalychnis consists of six currently recognized species (Duellman 2001, Faivovich et al. 2005). Our study species were Agalychnis annae, A. callidryas, A. moreletii, A. saltator, A. spurrelli, and Pachymedusa dacnicolor. Pachymedusa is a monotypic genus that is closely related to Agalychnis (Faivovich et al. 2005, Wiens et al. 2005, 2006). We also determined the undisturbed hatching pattern and onset of hatching competence of Cruziohyla calcarifer, a more distant outgroup within phyllomedusine hylids (Faivovich et al. 2005, Wiens et al. 2006). We did not pursue field studies on the rare Agalychnis litodryas (Duellman 2001; Global Amphibian Assessment, information available online $){ }^{4}$ Our molecular analyses suggest that this species is almost identical to $A$. spurrelli, and phenotypically these species differ only in coloration (Duellman 2001).

Like all other phyllomedusine hylids, the species included in this study have terrestrial eggs, laid on vegetation or other structures overhanging water, and aquatic tadpoles (Duellman 1968, Cannatella 1980, 1982, Haddad and Sawaya 2000, Duellman 2001, Neckel-Oliveira and Wachlevski 2004, Prado et al. 2005). The species of Agalychnis and Pachymedusa differ, however, in their geographic distribution and breeding phenology. Consequently, we conducted fieldwork on different species in different localities and at different times and, in some cases, using different local predator species (summarized in Appendix A). Although these differences preclude some direct statistical comparison among species, each set of experiments conducted on each species had its own controls, allowing us to broadly compare responses to egg-stage risks and trade-offs with larval-stage risks. Data on the responses

${ }^{4}$ 〈http://www.globalamphibians.org of $A$. callidryas and $A$. spurrelli to flooding and snake attacks have been reported elsewhere (Warkentin 1995, 2002, Gomez-Mestre and Warkentin 2007), but are included here for comparative purposes.

Agalychnis annae, A. callidryas, A. moreletii, and $C$. calcarifer breed more or less continuously throughout the rainy season (approximately from May to November), with an initial peak of reproduction following the first strong rainfalls (Lee 2000, Duellman 2001, Savage 2002). They can also breed year-round in areas with no marked dry season (I. Gomez-Mestre, personal observation). In contrast, $A$. saltator and $A$. spurrelli are explosive breeders (Scott and Starret 1974, Roberts 1994). Their reproductive activity takes place a few times each rainy season, in bursts that recruit large assemblages of frogs to the breeding ponds (Donnelly and Guyer 1994, Roberts 1994, Savage 2002, Kubicki 2004). Little or no breeding activity occurs during most of the rainy season, even when climatic conditions are appropriate for syntopic congeners to breed. Pachymedusa dacnicolor is not an explosive breeder, but occurs in xeric areas with a short wet season and sparse rainfall (Duellman 2001), and hence it breeds opportunistically following episodes of rain (I. Gomez-Mestre, personal observation).

\section{Onset of hatching competence and the pattern of undisturbed hatching}

To test for variation in the magnitude of plasticity in hatching timing among species, we determined the proportional capacity for hatching acceleration for each species. We calculated the capacity for hatching acceleration for each clutch as ("modal hatching time" minus "earliest induced hatching time")/"modal hatching time" (Fig. 1).

To assess inducible and spontaneous hatching timing, we collected 12-15 newly laid clutches of each species of Agalychnis and Pachymedusa and four of C. calcarifer from their natural breeding sites. We mounted each clutch on a plastic card and set it inside a $250-\mathrm{mL}$ plastic cup containing $3 \mathrm{~mm}$ of pond water. Clutches were maintained in open-air laboratories, under ambient temperature, humidity, and photoperiod for their respective localities and were misted with rain water every few hours to maintain hydration. Embryonic development is highly synchronous within and among egg clutches at a given site in all seven species (Warkentin 1999, 2002; I. Gomez-Mestre, personal observation). However, external gill regression, which is used as a developmental marker in staging tables (Gosner 1960), is highly plastic (Warkentin 2000a). Therefore, following Warkentin (1999), we used age within the plastic hatching period as a proxy for developmental stage.

To determine the onset of hatching competence (the earliest time when hatching could be induced), we removed five embryos (two for $C$. calcarifer) from each clutch early in development and placed them in a $4 \mathrm{~cm}$ 
diameter petri dish on moistened filter paper. Based on external morphology, embryos in the petri dishes developed synchronously with those that remained in the clutch. We conducted hatching induction trials every four hours starting at Gosner stage 22 (Gosner 1960), a full developmental stage prior to the earliest hatching observed in our pilot tests and prior research with these species. During each induction trial, two of the five eggs separated from each clutch (one in $C$. calcarifer) were submerged in plastic cups filled with pond water for 15 min. Meanwhile, we applied intermittent mechanical disturbance (Warkentin et al. 2006) to the three remaining eggs on the petri dish, using forceps to roll them and apply gentle pressure to simulate a predation event, being careful not to damage the egg capsule ourselves. Mechanical disturbance lasted for a total of $\sim 1$ min per egg, spread over a period of $3 \mathrm{~min}$. Such stimulation fell well within the range of temporal patterns observed for snake attacks on A. callidryas clutches (Warkentin 2005, Warkentin et al. 2006), and embryos failing to hatch in response to such stimuli would have been eaten.

We recorded the time of the first induced hatching in each clutch irrespective of whether it occurred during submergence or mechanical disturbance. The hatchling was preserved in $4 \%$ buffered formalin for morphological analysis. From the first induced hatching onwards, undisturbed clutches were censused every $4 \mathrm{~h}$, recording the number of spontaneous hatchings at each interval, until all normally developing eggs had hatched. We also preserved one embryo per clutch at the modal hatching time. Using digital image analysis (Image $\mathbf{J}$ version 1.33; National Institutes of Health, Bethesda, Maryland, USA) we measured embryo total length from photographs of preserved hatchlings for each species.

We tested for differences among species in their modal hatching time and capacity for hatching acceleration by fitting general linear models using SAS PROC MIXED (SAS Institute 2003), with species as a fixed factor. We used ANOVAs to compare total length of early induced embryos with that of embryos hatched spontaneously at the modal hatching time for each species. Data met parametric assumptions and no transformations were necessary.

\section{Egg clutch structure}

Egg clutch structure, particularly thickness, affects vibrational properties and thus could alter the information available to embryos in snake attacks (Snowdon 1968, Gomez-Mestre and Warkentin 2007). We therefore measured clutch thickness (as distance from the surface of the clutch to the substrate underneath, perpendicularly at the center of the clutch) with dial calipers to the nearest $0.5 \mathrm{~mm}$ in four $C$. calcarifer clutches and in 17-20 clutches of each of the other species. We also measured clutch thickness in four clutches of Hylomantis lemur found in Río Blanco
(Limón, Costa Rica). Hylomantis represents another genus of phyllomedusine hylids.

\section{Hatching response to flooding}

To test the effectiveness of the hatching response to underwater submergence we collected between 15 and 20 clutches of Pachymedusa and Agalychnis species, excepting A. callidryas and A. spurrelli, which had been tested before (Warkentin 2002, Gomez-Mestre and Warkentin 2007). We mounted all clutches as described above for undisturbed clutches (see Onset of hatching competence...). We randomly assigned five clutches per species to serve as controls and subjected the rest to flooding. All clutches were tested during the first morning after developing hatching competence. Experimental clutches were completely submerged by slowly pouring water into their cups, taking $5 \mathrm{~min}$ to fill the 250-mL volume. We poured the same volume of water into control cups but drain holes allowed it to flow through, preventing submergence of clutches (Warkentin 2002). We did not measure or control oxygen content of the water, but used pond water drawn from local breeding sites for each species. We counted the number of embryos hatched every $5 \mathrm{~min}$ for $1 \mathrm{~h}$, and also recorded the number of unhatched viable eggs after that time. For each species, we evaluated differences between hatching timing and proportion of embryos hatched in flooded and control clutches using a Cox regression model fitted in PROC PHREG (SAS version 8; SAS Intitute, Cary, North Carolina, USA). Cox regression is a method to analyze the occurrence and timing of events that does not require a priori assumptions regarding the probability distribution (Allison 1995). Clutches that still had viable, unhatched eggs $1 \mathrm{~h}$ after flooding were left submerged and checked periodically for the next few hours to assess overall hatching success of flooded clutches and whether viable embryos would drown.

\section{Hatching response to snake predation}

To assess the effectiveness of the hatching response of eggs to snake attacks and the effect of embryonic age on this response we experimentally exposed egg clutches of different ages to snake attacks. Snake predation trials on all species except Pachymedusa dacnicolor used the northern cat-eyed snake, Leptodeira septentrionalis. This species is a very common predator of Agalychnis eggs throughout the distribution of the genus (Duellman 1958). Trials on $P$. dacnicolor were conducted using another snake species of the same genus (Leptodeira maculata), because it was the most common snake observed at their breeding sites and because $L$. septentrionalis was locally uncommon. The use of a different Leptodeira species seems unlikely to strongly influence the results, given that escape hatching success of $A$. callidryas is consistent across four species of eggeating snakes in three different genera (K. M. Warkentin and A. T. D'Amato, unpublished manuscript). 
For each frog species, we used four to seven individual snakes, and snakes were fasted for at least $24 \mathrm{~h}$ between consecutive predation opportunities. Trials with $A$. callidryas and $A$. spurrelli used several of the same individual snakes and were reported previously (GomezMestre and Warkentin 2007). The sequence of predation trials was randomized with respect to clutch age to prevent bias due to learning in the snakes. Snakes were caught at the frog breeding ponds and kept individually in $50 \times 50 \times 100 \mathrm{~cm}$ mesh cages containing tree branches in open-air laboratories. We exposed hatching-competent clutches to snakes in their cages, with water containers placed below the clutches to collect hatchlings. Leptodeira septentrionalis never tried to feed on hatchlings in the water. Although aquatic foraging has not been reported for $L$. maculata, some individuals chased tadpoles in the water container. Therefore, during $P$. dacnicolor trials we placed a mesh screen over the water container, allowing hatchlings to fall through but preventing snakes from reaching them.

Escape hatching success was calculated as the fraction of viable eggs present at the start of an attack that hatched during the attack. We checked clutches and snakes frequently during the night to be able to exclude from escape success calculations any eggs that hatched spontaneously prior to contact with the snake. In most snake attacks, all eggs either hatched or were eaten. In the few instances in which a small number of unhatched eggs were left after an attack, these eggs hatched much later and were not included in calculations of escape hatching success. To test for effects of embryo age on escape hatching success for each frog species, we fitted generalized linear models with underlying binomial distributions and a logit link function using PROC GENMOD in SAS, using chi-square statistics to test the significance of changes in deviance (Crawley 1993). Because not all age classes were represented in all species, we compared hatching success among species constraining the analysis to ages (relative to modal hatching age) for which we had data on all species. With the underlying error distributions appropriately modeled as binomial, no data transformation was necessary for survivorship data in this or any other set of experiments.

\section{Vulnerability to an aquatic predator}

To test for a cost of premature hatching, we exposed hatchlings of different ages to fish predation. The number of age classes tested varied across species depending on the breadth of the plastic hatching period, ranging from three nights before modal hatching time to two nights after. Predation trials were conducted in round plastic containers filled with $3.25 \mathrm{~L}$ pond water, containing leaf litter to half the water depth, and a single fish. Each replicate for each age class used 10 newly hatched tadpoles from two to five equal-aged clutches, mechanically induced to hatch in the evening and placed immediately into the fish container. All hatchlings were in Gosner (1960) stage 23. Surviving hatchlings were counted after $24 \mathrm{~h}$, and fish length and gape size were measured for use as covariates to control for differences in predator size. Trials with A. annae, A. spurrelli, and $A$. saltator were all carried out using the same species of poeciliid fish, Poecilia gillii, the most common freshwater fish in Costa Rica (Bussing 2002). As P. gillii is far less common in Mexico and Guatemala, we used other ecologically similar, comparably sized, locally abundant poeciliids that were syntopic with the targeted frog species for trials with other species (Poeciliopsis gracilis for A. moreletii in Guatemala and Poecilia sphenops for $P$. dacnicolor in Mexico). Trials with A. callidryas were conducted earlier with another ecologically and morphologically similar, locally abundant poeciliid, Brachyraphis rhabdophora. These trials were originally reported in Warkentin (1995), and trials with A. spurrelli were reported in Gomez-Mestre and Warkentin (2007). We fitted generalized linear models with underlying binomial distributions to test for age effects on hatchling survival independently for each frog species using PROC GENMOD. We included fish size as a covariate when doing so improved the goodness of fit of the model, evaluated using the Akaike Information Criterion (Burnham and Anderson 2002).

\section{Molecular data and analysis}

Recent phylogenetic analyses of hylid frogs based on multiple nuclear and mitochondrial genes show strong support for placing Agalychnis within Phyllomedusinae and for placing Phyllomedusinae and Pelodryadinae as monophyletic sister taxa (Faivovich et al. 2005, Wiens et al. 2005, 2006). In the present study we included all six species of Agalychnis, as well as representatives of the phyllomedusine genera Cruziohyla (C. calcarifer), Hylomantis (H. lemur), Pachymedusa (P. dacnicolor), and Phyllomedusa (P. tomopterna). For a more distant outgroup, we also included four representatives of Pelodryadinae (Cyclorana manya, Litoria aurea, Litoria caerulea, and Nyctimystes foricula). Specimen localities and voucher numbers are given in Appendix B. Most tissues of Agalychnis were obtained from tail clips from preserved tadpoles used in analyses of hatching plasticity.

For each of the 14 species, we sequenced up to four nuclear genes (exon 2 cellular myelocytomatosis [c-myc], proopiomelanocortin A [POMC], recombinase activating gene 1 [RAG-1], tensin 3 [TNS3]) and three mitochondrial genes, including some adjacent tRNAs (mitochondrial ribosomal small subunit [12S], cytochrome $b$ [cyt-b], NADH dehydrogenase subunit I [ND1]). Basic properties of these genes are given in Table 1, and primers are given in Appendix C. In some cases, we were unable to amplify a gene for a particular species despite repeated attempts, and these taxa were treated as having missing data for these genes in the combined analysis. For some individuals and genes, sequences were previously published (mostly from 
TABLE 1. Summary of genes used in phylogenetic analyses of Agalychnis treefrogs and related species, including the best-fitting likelihood model and the optimal partitioning strategy within the gene (selected by comparison of Bayes factors).

\begin{tabular}{lccccc}
\hline \hline \multicolumn{1}{c}{ Gene } & $\begin{array}{c}\text { No. total characters } \\
\text { (included only) }\end{array}$ & $\begin{array}{c}\text { No. variable } \\
\text { characters }\end{array}$ & $\begin{array}{c}\text { No. parsimony- } \\
\text { informative characters }\end{array}$ & Likelihood model & Partitions \\
\hline Mitochondrial & & & & & \\
12S & 838 & 195 & 106 & GTR + I $+\Gamma$ & stems, loops \\
cyt-b & 559 & 241 & 184 & GTR + I $+\Gamma$ codon \\
ND1 & 1158 & 456 & 336 & GTR + I + & stems, loops, codon \\
Nuclear & & & & & none \\
c-myc, exon & 434 & 76 & 20 & HKY + I & codon \\
POMC & 522 & 114 & 59 & GTR + I & codon \\
RAG-1 & 952 & 173 & 94 & HKY + I & codon \\
TNS3 & 543 & 108 & 49 & HKY \\
\hline
\end{tabular}

Notes: For each of the 14 species, we sequenced up to four nuclear genes (exon 2 cellular myelocytomatosis [c-myc], proopiomelanocortin A [POMC], recombinase activating gene 1 [RAG-1], tensin 3 [TNS3]) and three mitochondrial genes, including some adjacent tRNAs (mitochondrial ribosomal small subunit [12S], cytochrome $b$ [cyt-b], NADH dehydrogenase subunit I [ND1]). Likelihood models include the following: GTR, general time reversible model; HKY, Hasegawa, Kishino, and Yano model; I, proportion of invariant sites; $\Gamma$, gamma distribution of rates.

Wiens et al. 2005). GenBank numbers for both new and published sequences are listed in Appendix D. We used standard methods of DNA extraction and polymerase chain reaction (PCR) amplification, and purified PCR products were sequenced using an ABI 3100 automated sequencer (Applied Biosystems, Foster City, California, USA). Alignment of protein-coding sequences was done by eye and was unambiguous. Alignments for $12 \mathrm{~S}$ and regions adjacent to ND1 were fitted to the alignments of Wiens et al. (2005), using Clustal X 1.8.1 (Thompson et al. 1994).

Our primary approach for estimating the phylogeny was a partitioned Bayesian analysis of the combined data, based on a single individual per species. However, several additional analyses were performed. First, we performed separate parsimony and Bayesian analyses of each gene. For each gene, we used MrModeltest version 2.0 (Nylander 2004) to identify the best-fitting model of sequence evolution (utilizing maximum-likelihood model fitting with the Akaike Information Criterion [AIC]). We compared Bayes factors to determine whether additional partitions (e.g., stems and loops, different codon positions) were supported within each gene, using the harmonic mean of the log-likelihoods from Bayesian analyses with and without partitions (Nylander et al. 2004, Brandley et al. 2005, Wiens et al. 2005). Partitions within genes were only utilized if the increase in model fit was very strong for the partitioned analysis (Bayes factor $\geq 10$ ) relative to the unpartitioned analysis. Stems and loops for $12 \mathrm{~S}$ and ND1 were identified following Wiens et al. (2005). Each Bayesian analysis used two replicate searches of two million generations each, with default priors. Bayesian analyses were implemented using MrBayes version 3.1.2 (Huelsenbeck and Ronquist 2001). Clades with posterior probabilities $(\mathrm{Pp}) \geq 0.95$ were considered strongly supported (e.g., Wilcox et al. 2002, Alfaro et al. 2003, Huelsenbeck and Rannala 2004). For each Bayesian analysis, two replicate analyses were run, and the posterior probability distribution (and likelihood values for testing partitions) were based on the pooled post-burn-in trees from the two paired analyses. The approximate burn-in point was determined based on similar plateaus in likelihood values over time for each search (indicating that the two searches had converged on similar results).

Parsimony analyses were performed using PAUP* version 4.0b10 (Swofford 2002), using heuristic searches with 100 random taxon addition sequence replicates. Nonparametric bootstrapping was used to evaluate clade support (Felsenstein 1985a), and clades with bootstrap values $\geq 70 \%$ were considered strongly supported (Hillis and Bull 1993).

Prior to combining data from different genes, we evaluated whether there were clades that were strongly supported and in conflict between genes, possibly indicating mismatch between gene and species phylogenies (following Wiens 1998). We also performed Bayesian analyses of the combined nuclear genes and the combined mitochondrial genes to identify possible cytonuclear genealogical discordance. Strongly supported conflicts involved clades that were incongruent between two or more genes but had Bayesian (Pp) $\geq$ 0.95 in each data set (based on the Bayesian analysis with the best-fitting partitioning strategy).

Although our primary analyses used a single individual per species, we also sequenced multiple individuals from several species for several genes. In all cases, these individuals clustered with conspecific individuals, suggesting that more extensive intraspecific sampling would yield an identical interspecific phylogeny.

\section{Phylogenetic comparative analyses}

To analyze the evolution of adaptive hatching plasticity and its covariation with other traits, we reconstructed the evolution of four traits on the phylogeny: (1) capacity for hatching acceleration, (2) embryo escape success in snake attacks, (3) clutch thickness, and (4) breeding phenology. Because all 
normally developing embryos hatched from flooded clutches in all species (see Results), the response to flooding was uniform across the species analyzed and required no reconstruction. The evolution of all other traits was reconstructed using the topology and branch lengths from the combined, partitioned Bayesian analysis. We used both parsimony and maximum likelihood for the reconstruction of breeding phenology (discrete trait) using Mesquite 1.12 (Maddison and Maddison 2006). We used linear generalized least squares (GLS; Martins and Hansen 1997) for continuous variables (capacity for hatching acceleration, escape success in snake attacks, and clutch thickness) using Compare $4.6 \mathrm{~b}$ (Martins 2004). The GLS method is equivalent to maximum likelihood reconstruction of a continuous character (Martins 1999). Maximum likelihood and GLS reconstructions used the branch lengths averaged from the post-burn-in trees from the Bayesian analysis of the combined data. Likelihood analyses of discrete traits used a one-rate model, assuming a single rate for both gains and losses. Likelihood reconstruction of a given discrete state for a given branch was considered significantly supported if the likelihood of one state was favored over the other by 2.0 or greater log-likelihood units (equivalent to a likelihood-ratio test; Pagel 1999).

For reconstruction of escape success we included only the six species for which we had experimental data $(P$. dacnicolor and all Agalychnis excepting the rare $A$. litodryas). Clutch thickness reconstruction used the six species for which we had experimental data plus Hylomantis lemur. Based on previous studies (Scott and Starret 1974, Roberts 1994, Lee 2000, Duellman 2001, Savage 2002) and our own observations, the species studied either breed more or less continuously during the entire rainy season ("prolonged breeding") or breed in a few, short pulses in which large numbers of breeding adults (hundreds to thousands) congregate at once ("explosive breeding"). Hence, breeding phenology was coded as a discrete variable where $1=$ prolonged breeding and $0=$ explosive breeding.

We tested correlations among traits using phylogenetic generalized least-square means analyses (PGLS; Martins and Hansen 1997) in Compare 4.6b (Martins 2004), which allows tests for correlations between two continuous traits and between a discrete independent variable and a continuous dependent variable (Martins 2004). These tests of association among traits had low statistical power because we could only include the six species for which we had experimental data on escape success in snake attacks. Nevertheless, the power was sufficient to detect several significant correlations. Analyses were conducted using the topology and average length of each branch from the post-burn-in trees obtained from the combined Bayesian analysis. Analyses were also conducted on an alternate tree (see Results: Phylogeny reconstruction). To assess whether embryo responses to different types of risk had evolved concurrently or independently, we tested for correlation between escape success (proportion of eggs surviving) in flooding and snake attacks. We also tested the correlation between escape success in snake attacks and average clutch thickness for a species, because biomechanical constraints on vibrational cues in thinner clutches may be associated with reduced embryo responses to snakes. We also tested for a correlation between breeding behavior and clutch thickness and between breeding behavior and escape success in snake attacks.

We estimated levels of phylogenetic conservatism (i.e., similarity among species over time) for the capacity for hatching acceleration, escape hatching success in snake attacks, and hatching success in flooding. Two different estimates of phylogenetic conservatism were calculated. First, we calculated the average divergence standard deviation of the descendent trait means, $D$, using the analysis of traits (AOT) module of the Phylocom software (version 3.40; Webb et al. 2006). If closely related species were highly divergent, there would be many large contrasts near the tips of the tree, whereas divergence would be small when closely related species resemble one another. Second, we calculated the quantitative convergence index (QVI; Ackerly and Donoghue 1998, Ackerly and Reich 1999, Kembel and Cahill 2005) for all three traits after 1000 iterations, as implemented in Cactus 1.13 (Schwilk 2001, Schwilk and Ackerly 2001). The QVI is calculated as tree length minus the minimum amount of character change over the entire range of character change and is equivalent to $1-$ retention index (Archie 1996, Ackerly and Donoghue 1998). It measures the degree of phylogenetic conservatism observed for a trait relative to that observed in trees with randomized trait values. The QVI values range from 0 to 1 , with 0 being maximal trait conservatism and 1 being low trait conservatism or high trait lability. Although we quantified different levels of conservatism in different traits, we acknowledge that we did not perform an explicit statistical test of these differences. However, to our knowledge, no direct test exists to compare differences in lability or conservatism between pairs of traits.

\section{RESULTS \\ Clutch structure}

Egg clutches varied in size and structure among the species studied (see Appendix E for photographs). Agalychnis annae, A. callidryas, A. moreletii, P. dacnicolor, C. calcarifer, and $H$. lemur laid discrete, generally elliptical, gelatinous clutches. Their clutch sizes were $70.6 \pm 6.3$ eggs (mean $\pm \mathrm{SE})(N=17$ clutches $), 40.9 \pm$ 2.1 eggs $(N=20$ clutches $), 71.5 \pm 4.8$ eggs $(N=20$ clutches), $76.2 \pm 7.1$ eggs $(N=20$ clutches $), 18.5 \pm 3.7$ eggs $(N=4$ clutches $)$, and $22.5 \pm 2.1$ eggs $(N=4$ clutches), respectively. The large amount of jelly surrounding and interspersed among eggs of these species resulted in relatively thick clutches (thicknesses, $16.0 \pm 0.7 \mathrm{~mm}, 10.0 \pm 0.5 \mathrm{~mm}, 11.2 \pm 0.9 \mathrm{~mm}, 13.3 \pm$ $0.5 \mathrm{~mm}, 13.1 \pm 0.7 \mathrm{~mm}$, and $7.1 \pm 0.3 \mathrm{~mm}$, respectively). In contrast, $A$. spurrelli egg clutches were laid as an 


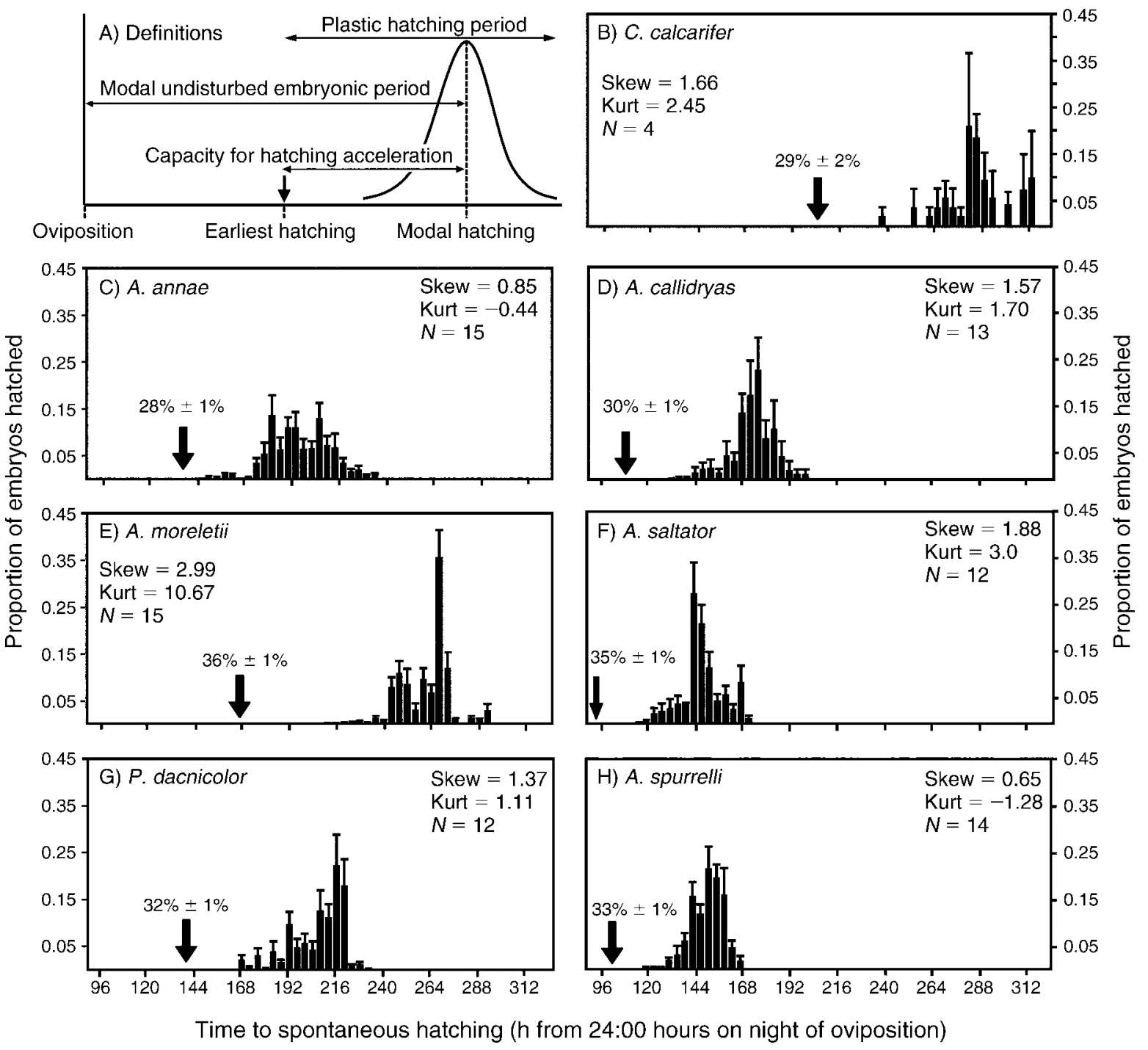

FIG. 1. (A) Plasticity in hatching timing is defined with respect to the timing of oviposition, earliest possible hatching, modal hatching, and latest hatching time. The plastic hatching period spans from the onset of hatching competence until the last hatching occurs. The capacity for hatching acceleration is the difference between modal hatching time and the onset of hatching competence. Acceleration of hatching is best expressed relative to the modal undisturbed, or control, embryonic period to facilitate among-species comparisons within and across studies. (B-F) Onset of hatching competence and spontaneous hatching patterns of undisturbed embryos of seven phyllomedusine treefrogs (Agalychnis, its sister taxon Pachymedusa, and Cruziohyla calcarifer, a basal phyllomedusine). Undisturbed hatching data (bars) are the proportion hatched (mean + SE) during each 4-h interval out of the initial number of eggs in each clutch. The number of clutches tested $(N)$ and skewness and kurtosis of the distribution of spontaneous hatching are indicated. Arrows show timing of earliest induced hatching (mean across clutches). Values associated with arrows indicate hatching acceleration (mean $\pm \mathrm{SE}$ ), calculated for each clutch as percentage of its modal hatching time (hours). The fraction of the normal embryonic period by which hatching could be accelerated was relatively similar across species (28-36\%), regardless of overall length of development. Agalychnis saltator and A. spurrelli spontaneously hatched earlier than syntopic A. callidryas. For some other species, differences in hatching timing may be due to temperature differences between their localities.

irregularly shaped monolayer with little associated jelly. Average egg mass size in A. spurrelli was $73 \pm 9.5$ eggs $(N=20$ clutches $)$, and clutches were only $4.4 \pm 0.1 \mathrm{~mm}$ thick. Like A. spurrelli, A. saltator eggs had very little jelly surrounding them, but most of the eggs were laid communally. Communal egg-laying resulted in large aggregations of eggs spreading over branches, leaves, trunks, mosses, and epiphyte roots in a continuous mass in which individual clutches (i.e., laid by individual females) were indistinguishable from one another (Appendix E). Only a small subset of eggs was laid as discrete, individual egg masses. As in A. spurrelli, A. saltator eggs were generally laid against the substrate in a monolayer, or rarely a bilayer, so that clutch thickness (4.9 $\pm 0.2 \mathrm{~mm}, N=20$ clutches) was only slightly thicker than the ovum diameter itself. 


\section{Onset of hatching competence and the pattern of undisturbed hatching}

The pattern of undisturbed, spontaneous hatching for each species is shown in Fig. 1. Embryos hatched mostly at night over the span of two to three days. Most species showed a strong peak (mode) of hatching on the second night after spontaneous hatching had begun, with the exception of $A$. annae, in which hatching was more gradual. Species differed in their average modal hatching age $\left(F_{6,78}=265.67, P<0.0001\right)$, with $A$. saltator and $A$. spurrelli hatching significantly earlier than any of the other species, and in particular, earlier than the syntopic A. callidryas $(24.1 \mathrm{~h}$ and $22.4 \mathrm{~h}$ earlier, respectively; post hoc Tukey tests, $P<0.001)$. Other differences in hatching timing between species studied at different sites may reflect temperature effects on developmental rates. Temperatures ranged from $20.5^{\circ} \mathrm{C}$ to $24.5^{\circ} \mathrm{C}$ in our Guatemalan sites (A. moreletii) and from $24.0^{\circ} \mathrm{C}$ to $28.5^{\circ} \mathrm{C}$ in our Mexican and Costa Rican sites. In Belize, the hatching timing of syntopic $A$. moreletii and $A$. callidryas is very similar (V. S. Briggs, personal communication).

Embryos of all species hatched prematurely in response to both mechanical disturbance and submergence underwater. All species achieved hatching competence soon after the embryos reached Gosner stage 23 (Gosner 1960), when the operculum forms across the venter (Pyburn 1963). This developmental stage, however, was reached almost a day earlier in A. saltator and $A$. spurrelli than in the next fastest developing species, the syntopic $A$. callidryas. The earliest induced hatching occurred between $28 \% \pm 1 \%$ and $36 \% \pm 1 \%$ prior to the modal hatching time, depending on the species (Fig. 1). This hatching acceleration differed significantly among species $\left(F_{6,78}=7.07, P<0.0001\right)$. The largest difference in hatching acceleration among species was $8 \%$, and post hoc Tukey tests showed that it was primarily due to differences between $A$. annae and $A$. moreletti and $A$. saltator. The observed lower capacity for hatching acceleration in $A$. annae may, however, be an effect of the more gradual distribution of spontaneous hatching, lacking a strong mode, rather than developmentally older early-induced hatching.

The earliest premature hatchlings were significantly smaller in total length than were spontaneously hatching tadpoles in all species (all tests $F_{1,18} \geq 19.98$, all $P<$ 0.0001; A. annae, $14 \%$ smaller; A. callidryas, $19 \% ; P$. dacnicolor, 21\%; A. moreletii, 18\%; A. saltator, 27\%; A. spurrelli, 13\%; see Appendix F for photographs). They also had more bulbous abdomens filled with large, undifferentiated yolk sacs and relatively shorter tails and were less active than spontaneous hatchlings (Appendix F; I. Gomez-Mestre and K. M. Warkentin, personal observations).

\section{Hatching response to flooding}

All species hatched in response to experimental flooding of the clutch the morning after they reached hatching competence. In all species, a significantly higher proportion of embryos hatched in submerged clutches than in controls (in air) within the 1-h observation period (Fig. 2, all $\chi^{2} \geq 37$, all $P<$ $0.0001)$. Over that time period, $>90 \%$ of submerged embryos hatched in all species except $A$. saltator and $A$. spurrelli, in which fewer embryos hatched $(69 \%$ and $60 \%$, respectively; $\chi^{2}=37$, df $\left.=5,54, P<0.0001\right)$. Although submerged $A$. saltator and $A$. spurrelli clutches hatched more gradually than those of other species, we cannot assess whether this reflects differences in the quality (oxygenation) of pond water used in experiments. All normally developing embryos in all species hatched within $3 \mathrm{~h}$ of submergence and none were killed. Therefore, we coded embryo hatching success in flooding as $100 \%$ in the comparative analyses.

\section{Hatching response to snake predation}

Escape hatching success in response to snake attacks increased significantly with age in all species $(A$. annae, $\chi^{2}=23.77, \mathrm{df}=2,11, P<0.0001 ;$ A. callidryas, $\chi^{2}=$ 25.22, df $=3,44, P<0.0001 ;$ A. moreletii, $\chi^{2}=84.03, \mathrm{df}$ $=3,44, P<0.0001 ;$ A. saltator, $\chi^{2}=4.01, \mathrm{df}=1,8, P=$ 0.045; A. spurrelli, $\chi^{2}=25.37, \mathrm{df}=1,14, P<0.0001 ; P$. dacnicolor, $\chi^{2}=17.33$, df $=2,11, P=0.0002$; see Fig. 3 for comparisons of specific ages in each species). To compare the overall hatching response of embryos to snake attacks across species and to test for age $\times$ species interactions, we fitted a model including only trials conducted at the age (in days) of modal hatching $(0 \mathrm{~d})$ and the night before $(-1 \mathrm{~d})$, because those were the only ages for which data were available for all species. The overall hatching response to snake attacks differed among species $\left(\chi^{2}=80.60\right.$, df $\left.=5,70, P<0.0001\right)$. Tukey post hoc tests indicated that $A$. spurrelli had significantly lower overall escape success than $A$. saltator $(P<0.05)$ and that these two had lower escape success than any of the other species $(P<0.01)$. There were no significant differences among the other species. The stage $\times$ species interaction term was also significant $\left(\chi^{2}=\right.$ 4.01, $\mathrm{df}=5,70, P<0.01$ ); escape success increased more between $1 \mathrm{~d}$ premature and the modal hatching age in $A$. saltator and $A$. spurrelli than in the other species.

For species that develop faster, a 1-d acceleration of hatching represents a larger fraction of the embryonic period. We therefore also conducted analyses on biologically relevant data partitions with respect to developmental stage, controlling for the false discovery rate (Garcia 2003, Verhoeven et al. 2005). Species differed significantly in escape success at the onset of hatching competence $\left(\chi^{2}=75.28, \mathrm{df}=5,40, P<0.0001\right.$; age $-3 \mathrm{~d}$ for $A$. moreletii, age $-2 \mathrm{~d}$ for $A$. annae, $A$. callidryas, and $P$. dacnicolor, and age $-1 \mathrm{~d}$ for $A$. saltator and $A$. spurrelli; see Fig. 3$)$. Post hoc tests indicated that $A$. callidryas showed higher escape success than $A$. annae, A. moreletii, A. saltator, and P. dacnicolor, that these four species did not differ from one another, and that all four had higher escape success than $A$. spurrelli. 


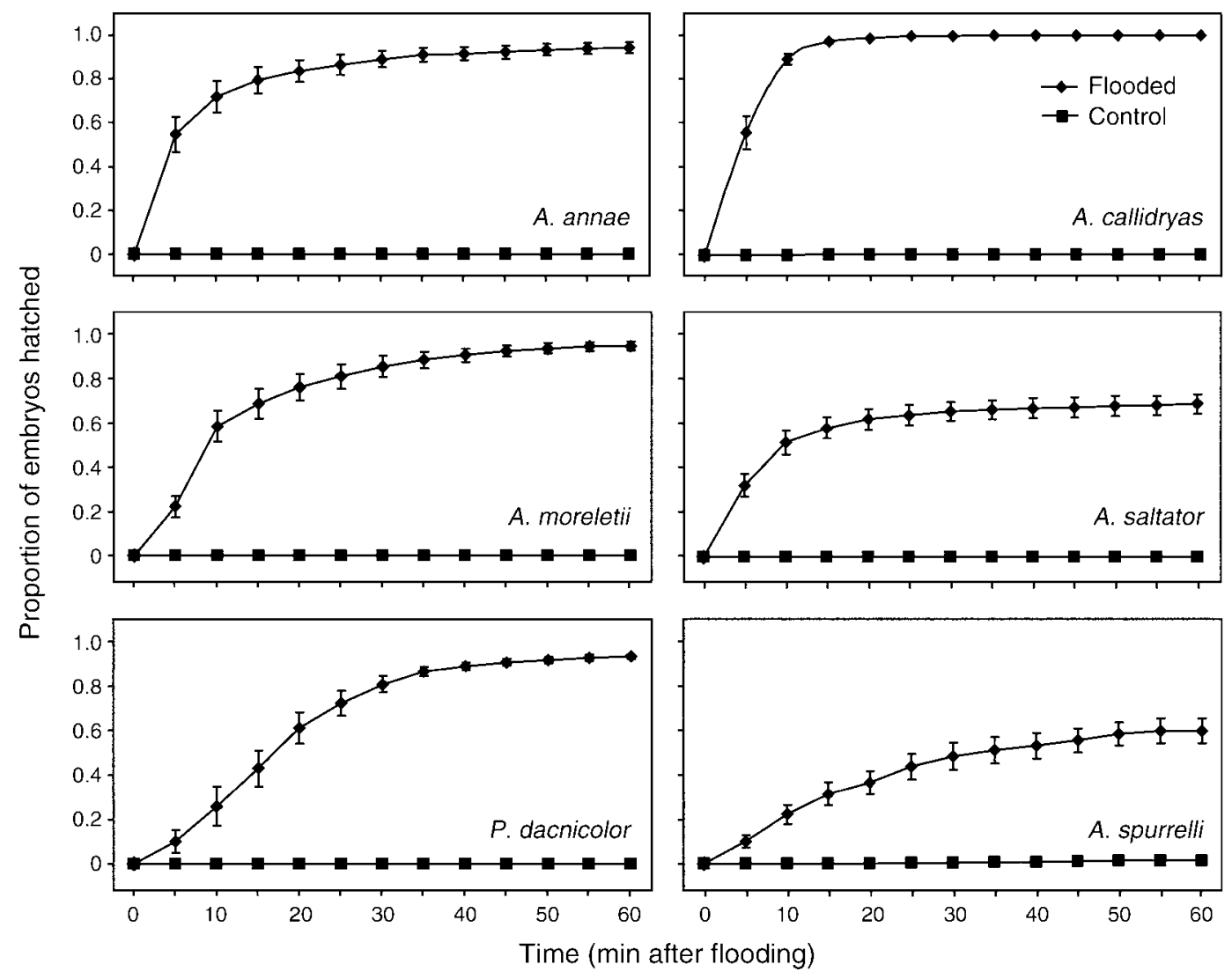

FIG. 2. Hatching pattern of egg clutches submerged in pond water 12-24 h after the onset of hatching competence ("flooded" treatment) and simultaneously monitored unflooded control clutches of six phyllomedusine treefrogs (Agalychnis and Pachymedusa). Data are the cumulative proportions hatched (mean $\pm \mathrm{SE}$ ). Data for $A$. callidryas and $A$. spurrelli are redrawn from Warkentin (2002) and Gomez-Mestre and Warkentin (2007), respectively. While A. saltator and A. spurrelli showed a slower response than the other species tested, all normally developing embryos in all species hatched within $3 \mathrm{~h}$ after submergence.

Species also differed significantly in escape success at modal hatching age $\left(\chi^{2}=103.56, \mathrm{df}=5,36, P<0.0001\right)$, as A. saltator and A. spurrelli achieved only $55 \% \pm 9 \%$ and $28 \% \pm 4 \%$ escape success, while the other four species averaged $78 \% \pm 1 \%$ escape success.

\section{Vulnerability to an aquatic predator}

Hatchling survival with a predatory fish increased with hatching age in all six species $\left(A\right.$. annae, $\chi^{2}=32.64$, $\mathrm{df}=4,23, P<0.0001 ;$ A. callidryas, $\chi^{2}=23.21, \mathrm{df}=3$, 15, $P<0.0001 ;$ A. moreletii, $\chi^{2}=15.44, \mathrm{df}=3,27, P=$ $0.0015 ;$ A. saltator, $\chi^{2}=6.65, \mathrm{df}=2,11, P=0.036 ; A$. spurrelli, $\chi^{2}=26.08, \mathrm{df}=1,9, P<0.0001 ; P$. dacnicolor, $\chi^{2}=75.08$, df $=2,22, P<0.0001$; see Fig. 3 for comparisons of specific ages in each species). This result suggests that there is a significant cost associated with premature hatching in these species.

\section{Phylogeny reconstruction}

The best-fitting model and partitioning strategy for each gene is provided in Table 1, and the phylogeny from the combined, partitioned Bayesian analysis is shown in Fig. 4A. There were no strongly supported conflicts among the three mitochondrial genes and almost none among the four nuclear genes. However, TNS3 showed strong support for a more basal placement of $A$. callidryas, which is not supported by the other nuclear or mitochondrial genes (results not shown). Separate analyses of the combined nuclear and combined mitochondrial genes yielded nearly identical and well-supported phylogenies (Fig. 4B, C) that differed only in the placement of $A$. saltator, either as the sister taxon of all other Agalychnis (mitochondrial) or sister of the $A$. annae-A. moreletii-A. callidryas clade (nuclear, supported largely by RAG-1). The combined analysis yielded a tree that was generally strongly supported and congruent with those from the separate analyses of the nuclear and mitochondrial data, except for the position of A. saltator. Given the strong support for the two alternate placements of this species, we consider its position on the tree to be somewhat unresolved because of conflicting signals from the mitochondrial and nuclear data sets, possibly due to incomplete lineage sorting in the nuclear gene RAG-1. Comparative analyses were conducted on both potential topologies. Use of the combined-data topology (Fig. 

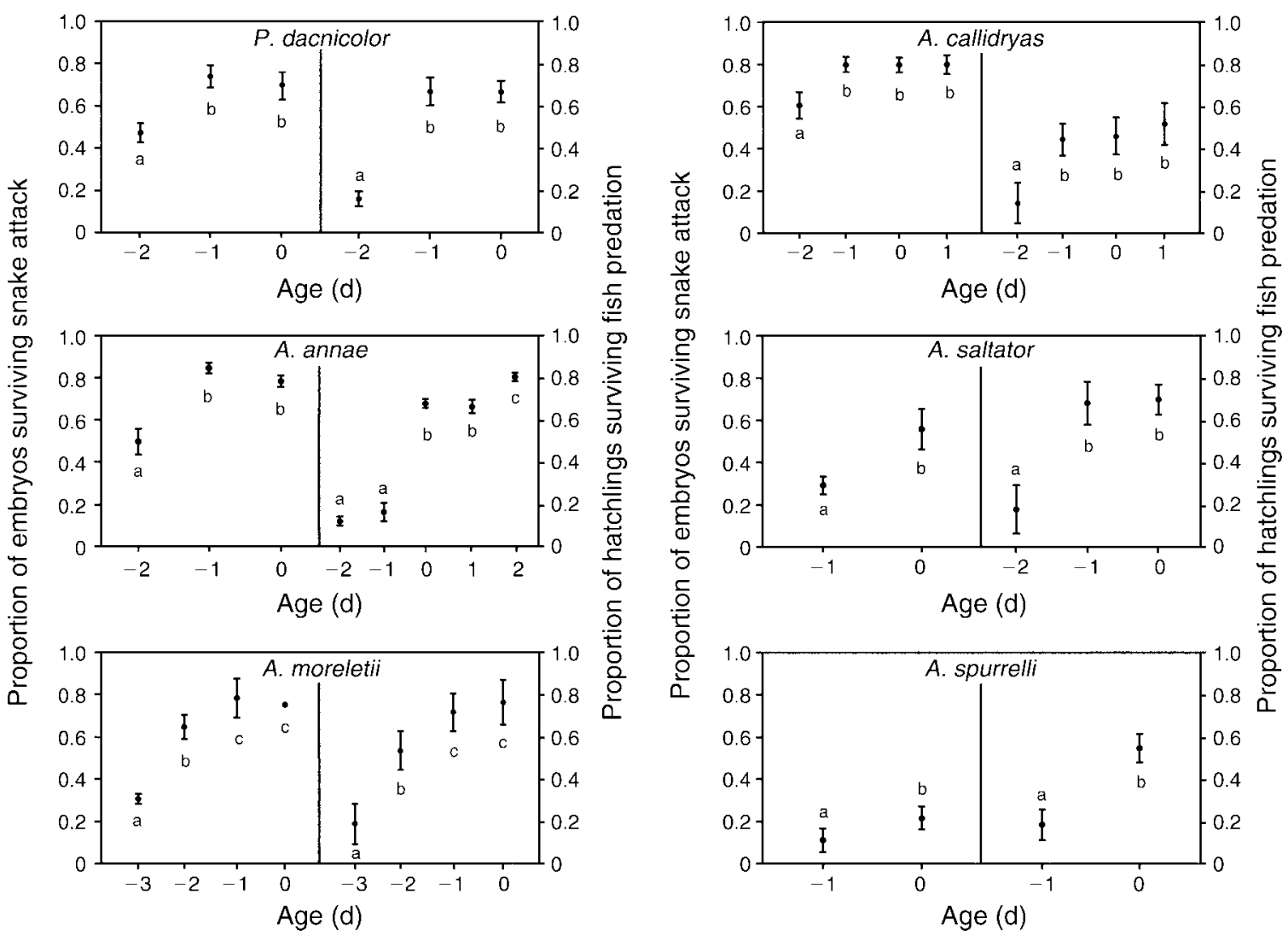

FIG. 3. Escape hatching success of embryos of six phyllomedusine treefrogs in attacks by cat-eyed snakes (left-hand panels) and hatchling survival over $24 \mathrm{~h}$ with a poeciliid fish (right-hand panels) at different ages. Age is shown relative to the modal hatching age $(0 \mathrm{~d})$ for each species. Different lowercase letters indicate significantly different escape hatching success or hatchling survival with age within species $(P<0.05)$ as indicated by post hoc tests. Left portions of panels in both columns: Snake predators were Leptodeira septentrionalis for all Agalychnis, and L. maculata for Pachymedusa dacnicolor. Data are proportions of eggs (mean $\pm \mathrm{SE}$ ) present at the start of the attack that hatched and escaped from the snake during the attack. Data for A. callidryas and A. spurrelli are redrawn from Gomez-Mestre and Warkentin (2007). Escape hatching success improved developmentally in all species and was lower overall in A. saltator and A. spurrelli. Right portions of panels in both columns: Predators were Poecilia gillii for Agalychnis annae, A. saltator, and A. spurrelli; Poeciliopsis gracilis for A. moreletii; Brachyraphis rhabdophora for A. callidryas; and Poecilia sphenops for Pachymedusa dacnicolor. Data for A. callidryas are redrawn from Warkentin (1995), and data for A. spurrelli are redrawn from Gomez-Mestre and Warkentin (2007). Hatchling survival improved developmentally in all species.

4A) or of a topology constrained to have $A$. saltator as sister species of the $A$. annae-A. moreletii-A. callidryas clade (supported by the nuclear data) did not alter the statistical results of the comparative analyses conducted. These results confirm and extend previous studies that included some of the species studied here (Faivovich et al. 2005, Wiens et al. 2005, 2006). Agalychnis is confirmed as a monophyletic group and the exclusion of C. calcarifer from Agalychnis (previously Agalychnis calcarifer) is corroborated (see also Faivovich et al. 2005). Pachymedusa dacnicolor is strongly supported as the sister taxon of Agalychnis.

\section{Evolutionary patterns and trait correlations}

Data on capacity for hatching acceleration, breeding phenology, clutch thickness, hatching success in flooding, and escape hatching success in snake attacks are summarized graphically on the phylogeny (Fig. 5). The capacity for hatching acceleration varied little across species, and GLS reconstruction of ancestral capacity for hatching acceleration ranged between 0.32 and 0.33 across all nodes. Agalychnis spurrelli and A. saltator differ from other Agalychnis and Pachymedusa in having minimally gelatinous clutches, explosive breeding behavior, and low escape hatching success in snake attacks. The GLS reconstruction of clutch thickness suggests that it was reduced in $A$. spurrelli and $A$. saltator and increased in the common ancestor of $A$. callidryas, A. moreletii, and A. annae (Fig. 5). However, the intermediate values reconstructed for the ancestors of A. spurrelli and A. saltator may be an artifact associated with the GLS method "averaging" the largely bimodal trait values of extant species (minimally gelatinous clutches in A. spurrelli and A. saltator and highly gelatinous clutches in all other species except $H$. lemur). 


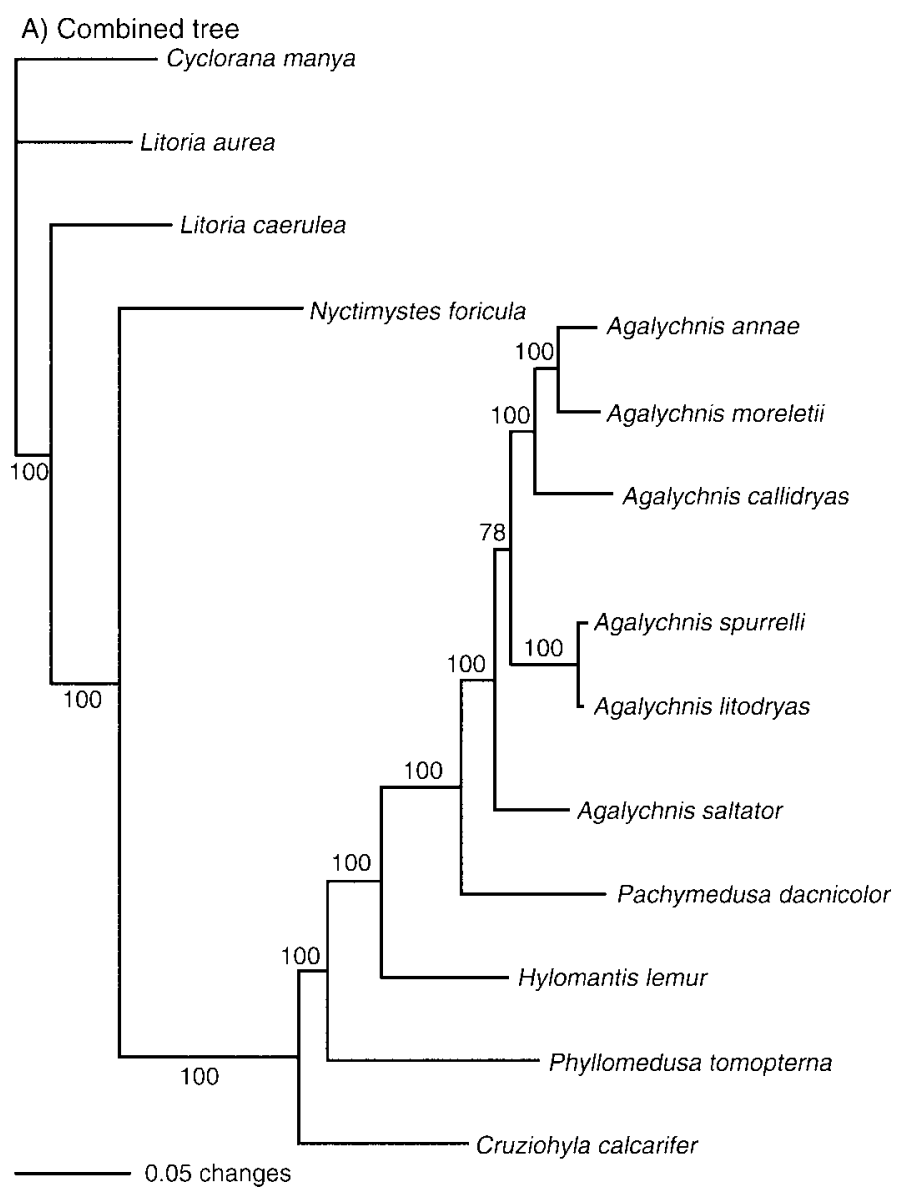

B) mtDNA tree

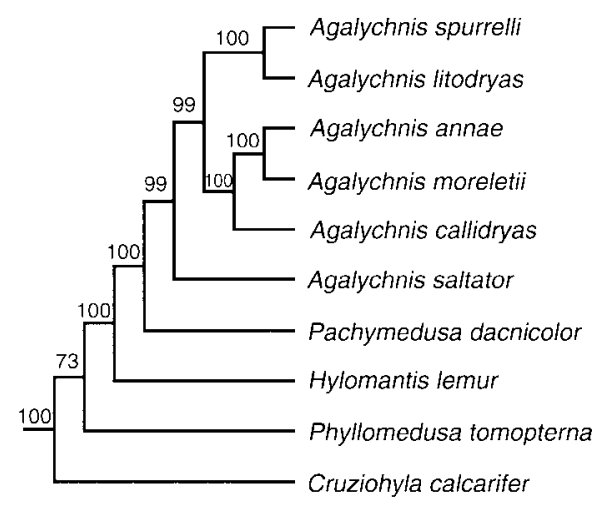

C) nucDNA tree

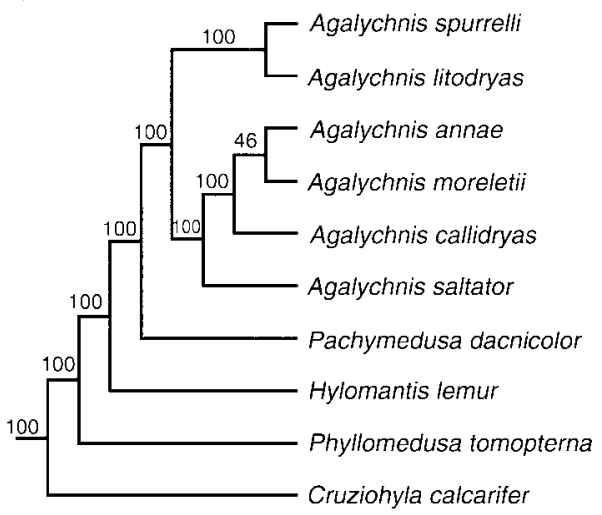

FIG. 4. Phylogeny of Agalychnis and other Phyllomedusinae. Four species of Pelodryadinae were used as an outgroup. (A) Tree from combined, partitioned Bayesian analysis of all molecular data, showing estimated branch lengths and outgroups $(C y c l o r a n a$, Litoria, and Nyctimystes). (B) Tree from combined, partitioned Bayesian analysis of the three mitochondrial genes. (C) Tree from combined, partitioned Bayesian analysis of the four nuclear genes. Mitochondrial and nuclear data showed incongruence in the placement of $A$. saltator, resulting in lower support for the corresponding node in the analysis combining nuclear and mitochondrial data. In all three trees, numbers associated with nodes indicate Bayesian posterior probabilities $(\times 100)$. The root is between Pelodryadinae and Phyllomedusinae, not within Pelodryadinae.

There are two equally parsimonious reconstructions for the evolution of breeding phenology: (1) it changed twice, independently going from prolonged to explosive in A. spurrelli and A. saltator or (2) it changed once from prolonged to explosive in the common ancestor of all Agalychnis and then reversed in the ancestor of the $A$. annae-A. moreletii-A. callidryas clade.

The GLS reconstruction of escape success in snake attacks was inconclusive, showing intermediate escape success at the base of Agalychnis and the nodes branching to A. spurrelli and A. saltator (Fig. 5). Therefore, there are three plausible scenarios for the evolution of embryo responses to snakes (regardless of which placement of $A$. saltator is used): (1) high responsiveness to snakes is derived and evolved twice independently, in $P$. dacnicolor and in the common ancestor of $A$. callidryas, A. moreletii, and A. annae; (2) high responsiveness to snakes is ancestral, was reduced in the common ancestor of all Agalychnis, and increased again in the common ancestor of A. callidryas, $A$. moreletii, and $A$. annae; or (3) high responsiveness to snakes is ancestral and has been secondarily reduced twice, in both $A$. saltator and A. spurrelli.

The capacity for hatching acceleration was highly conserved across Agalychnis and Pachymedusa $(D=2.3$; $\mathrm{QVI}=0.11)$. Escape hatching success in response to different risks, however, showed different levels of evolutionary conservatism. All embryos hatched during flooding in all species, whereas escape success in snake attacks showed substantial variation across species. Consequently, trait conservatism was much higher for hatching success in flooding $(D=0.02, \mathrm{QVI}=0)$ than for hatching success in snake attacks $(D=19.95, \mathrm{QVI}=0.87$ at $-1 \mathrm{~d} ; D=15.63$, QVI $=0.68$ at $0 \mathrm{~d})$.

The PGLS tests indicated that there is no correlation between hatching success during flooding and escape hatching success during snake attacks (Table 2). Higher escape success in snake attacks at one day premature 

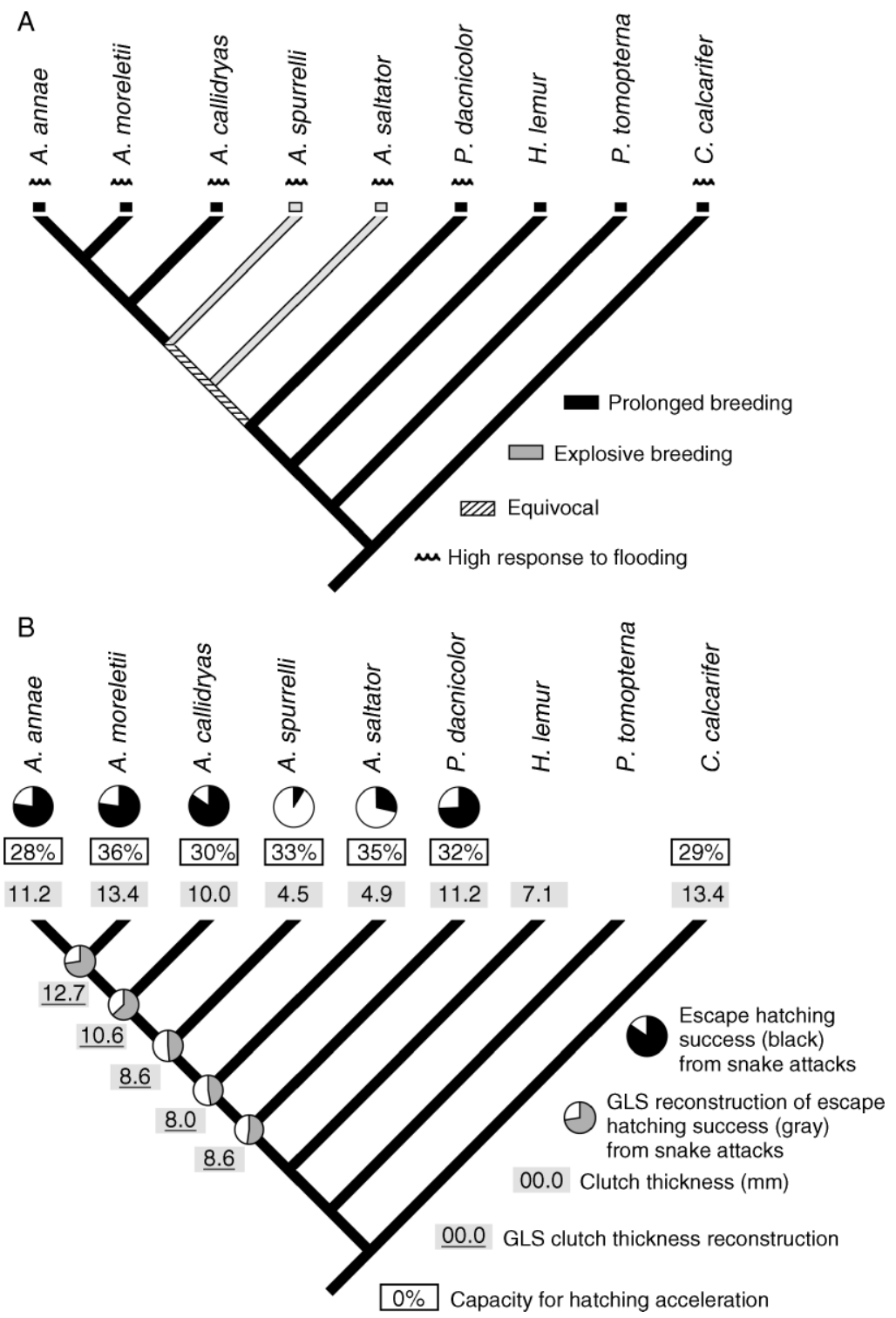

FIG. 5. Evolutionary reconstruction of hatching-related traits in Agalychnis and related genera. Trait values at branch tips are species averages; values at nodes indicate estimated ancestral states. Ancestral values for discrete traits were reconstructed based on parsimony and maximum likelihood estimates, although only parsimony reconstructions are shown here. Continuous characters were reconstructed using linear generalized least squares (GLS). Branch lengths from the combined Bayesian analysis of all molecular data were used in all cases. (A) Breeding phenology and embryo hatching response to flooding. (B) Capacity for hatching acceleration (open rectangles), clutch thickness (shaded rectangles), and escape success in snake attacks one day before the modal hatching age (pie charts). The reconstructed hatching acceleration was similar across all nodes (range 32-33\%) and is not shown. Capacity for hatching acceleration and hatching response to flooding were less labile than escape hatching success in snake attacks. Agalychnis saltator and A. spurrelli show lower hatching success in snake attacks than all other species, including the syntopic $A$. callidryas. These two species breed explosively and have minimally gelatinous clutches, traits significantly correlated with lower escape hatching success in snake attacks.

was, however, significantly correlated with clutch thickness and prolonged breeding behavior (Table 2, Fig. 5). At the modal hatching age, correlation between escape success in snake attacks and breeding phenology was still significant, but its correlation with clutch thickness was marginally nonsignificant. Breeding phenology and clutch thickness were significantly correlated as explosive breeders had markedly less gelatinous clutches $\left(r=0.90, R^{2}=0.81, P=0.015\right.$; Fig. 5).

\section{Discussion}

Adaptive phenotypic plasticity is a frequent characteristic of organisms evolving in heterogeneous environments (Stearns 1989, Pigliucci 2001, West-Eberhard 
TABLE 2. Results of phylogenetic comparative tests for associations between escape hatching success in two risk contexts and between escape success in snake attacks and two reproductive traits in the phyllomedusine treefrogs Agalychnis and Pachymedusa.

\begin{tabular}{|c|c|c|c|c|c|c|c|c|}
\hline \multirow[b]{3}{*}{ Variable } & \multicolumn{8}{|c|}{ Escape success in snake attacks } \\
\hline & \multicolumn{4}{|c|}{ At $1 \mathrm{~d}$ premature } & \multicolumn{4}{|c|}{ At the modal hatching age } \\
\hline & $\overline{M L} \alpha$ & $r$ & $R^{2}$ & $P$ & $\mathrm{ML} \alpha$ & $r$ & $R^{2}$ & $P$ \\
\hline Hatching success in flooding & 5.40 & 0 & & NS & 5.40 & 0 & & NS \\
\hline Clutch thickness & 7.22 & 0.91 & 0.83 & 0.012 & 13.18 & 0.78 & 0.61 & 0.056 \\
\hline Breeding phenology & 15.5 & 0.96 & 0.93 & 0.002 & 14.74 & 0.90 & 0.81 & 0.015 \\
\hline
\end{tabular}

Notes: ML $\alpha$ is the maximum likelihood estimate of evolutionary constraint (Martins 2004). When $\alpha$ is small, generalized least squares (GLS) approximates Felsenstein's independent contrasts analysis (Felsenstein 1985b). When $\alpha$ is large, comparative data are less dependent on phylogeny and approximate a raw, nonphylogenetic correlation analysis. Significant and marginally significant correlations are indicated with boldface and italic type, respectively.

2003, DeWitt and Scheiner 2004), but to date few comparative studies have examined the evolutionary history of plasticity. Many hypotheses about the evolution of plastic responses can only be addressed by detailed phylogenetic comparative analyses. Here, we combine phylogenetic information and field-collected data on the ability of treefrog embryos to alter their timing of hatching in response to environmental conditions.

We find strong evolutionary conservatism in overall plasticity (i.e., range of possible phenotypes). Specifically, the capacity for hatching acceleration has been highly conserved over tens of millions of years through speciation events and different environments. This conserved plasticity in hatching timing is seemingly associated with the maintenance of a trade-off between egg-stage and larval-stage risks. Despite this high conservatism in the overall capacity for plasticity, the sensitivity of the plastic response to differently cued risks has evolved independently. Thus, hatching in response to flooding (cued by hypoxia) is also highly conserved, whereas escape hatching in snake attacks (cued by vibration) appears to be evolutionarily more labile, changing dramatically between closely related, syntopic species. We find a significant association between escape success in egg predator attacks and both clutch structure and breeding phenology. We hypothesize that changes in clutch structure may have had pleiotropic effects on the hatching response to snake attacks and that changes in breeding phenology could alter selection by egg predators. We conclude that sensitivity to different environmental cues leading to the same adaptive plastic response may evolve independently, even if the general capacity for plasticity remains the same over long periods of evolution.

\section{Evolution of adaptive hatching plasticity}

The ability to accelerate hatching in response to eggstage risk was present in all species studied, and all species experienced trade-offs between egg- and larvalstage risks. The capacity for hatching acceleration, relative to the modal hatching time, showed little evolutionary variation within this clade (28-36\%; Fig.
5). Given the similarity of this trait between the basal Cruziohyla and the more derived Agalychnis and Pachymedusa, it appears to have remained relatively stable for at least 34-50 million years of evolutionary history (based on estimated divergence times for Phyllomedusinae from Wiens et al. [2006]), through multiple speciation events and through substantial changes in other traits, such as habitat type (e.g., xeric lowlands [Pachymedusa dacnicolor], humid montane forests $[$ A. moreletii]) and breeding phenology (explosive, prolonged). Hatching plasticity thus represents not an unusual, apomorphic trait in a single species of leafbreeding treefrog (A. callidryas), but rather an ancient, widely conserved capacity in phyllomedusine hylids. Other examples of hatching plasticity in other taxa (Wedekind 2002, Moreira and Barata 2005, Ireland et al. 2007) may also represent the maintenance of an ancient origin of plasticity in these groups, rather than rare specialized cases of embryo responses to risk.

The same induced defensive phenotype may be produced in response to various risks, and our data indicate that plastic responses to different risks may have different evolutionary histories. The hatching response to flooding is strong and highly conserved across Agalychnis and Pachymedusa. Flooding is lethal for young eggs that are incapable of hatching (Pyburn 1970, Warkentin 2000b, Gomez-Mestre and Warkentin 2007), presumably due to suffocation. The fact that the relatively basal $C$. calcarifer hatched in response to flooding along with the flooding response in Agalychnis and Pachymedusa suggest that such a response was likely present in the ancestral phyllomedusine and has been conserved in its descendants for at least 34-50 million years (Wiens et al. 2006). Local hypoxia is thought to be the proximate cue for most terrestrial eggs that hatch when flooded (DiMichele and Taylor 1980, Petranka et al. 1982, Warkentin 2002). Hypoxia stimulates hatching in invertebrates (Gjullin et al. 1941, Fallis and Snow 1983, Miller 1992), fishes (DiMichele and Taylor 1980, Latham and Just 1989), amphibians (Petranka et al. 1982, Bradford and Seymour 1988), and at least one reptile (Losos et al. 2003). Thus, a hatching response to hypoxia is either a very ancient trait or has evolved 
repeatedly. Indeed, the fact that some aquatic eggs in fishes and frogs accelerate hatching in response to hypoxia (e.g., Latham and Just 1989, Seymour et al. 2000, Czerkies et al. 2001) suggests that such a response could even have been present prior to the evolution of arboreal eggs in phyllomedusines.

In contrast, the response to snake predation has changed substantially twice in the last $\sim 15-21$ million years in the Agalychnis-Pachymedusa clade (dates based on Wiens et al. [2006]). Therefore, some element(s) in the information pathway linking snake attack to risk assessment and the escape hatching response has changed twice in this clade, without altering either the underlying developmental capacity for hatching at different stages or the pathway linking hypoxic stress to hatching behavior. Premature hatching in response to snakes is cued by mechanical disturbance of the eggs (Warkentin 2005). Like the Agalychnis species that escape well from snakes, and in strong contrast to $A$. spurrelli, Cruziohyla calcarifer embryos were highly responsive to mechanical cues in our tests of the onset of hatching competence. This suggests that they may also escape well in snake attacks and that a strong response to snakes may, like the strong response to flooding, be ancestral in phyllomedusines. Although our data do not resolve whether the embryo response to flooding or snake attack evolved first or they evolved concurrently, both traits appear to be relatively ancient. Moreover, they are not correlated and thus evolve independently. The hatching response to snake attacks shows greater evolutionary lability than either the overall capacity for hatching acceleration or the response to flooding (Fig. 5).

\section{Divergence of plastic responses among closely related, sympatric species}

Many studies have documented evolutionary divergence of adaptive plasticity among closely related species exposed to different regimes of environmental heterogeneity (Lee et al. 1986, Leips and Travis 1994, Gotthard and Nylin 1995, Bell and Sultan 1999, Morey and Reznick 2000, 2004, Stoks et al. 2003). Conversely, we expect closely related species occupying similar habitats to share plasticity based on both similar selection and shared evolutionary history. However, syntopic larval newts show dissimilar behavioral and morphological responses to predators (Schmidt and Van Buskirk 2005). Similarly, we show that embryos of $A$. callidryas show striking differences in their response to snake predation relative to the syntopic $A$. saltator and A. spurrelli (which are very similar to one another), although the response is conserved across all other species studied despite greater phylogenetic and geographical distances.

The geographic distribution of $A$. callidryas is broad and encompasses the entire range of $A$. saltator and much of the range of $A$. spurrelli (Duellman 2001). Over this extended area of geographic overlap, these species co-occur at the same ponds and often lay eggs on the same plants. Snakes show no preference for $A$. callidryas eggs over $A$. spurrelli eggs, and we observed similarly high snake predation rates $(\sim 40 \%)$ on clutches of both species monitored simultaneously at a pond in southeastern Costa Rica (Gomez-Mestre and Warkentin 2007). Total snake predation rates, including $A$. callidryas clutches present without $A$. spurrelli, were also very similar. Snakes feed readily on eggs of $A$. saltator in captivity, and we have also observed snakes foraging on these eggs in the field (K. M. Warkentin and I. Gomez-Mestre, personal observation). Thus, environmental differences do not explain the low hatching success of $A$. spurrelli and $A$. saltator during snake attacks. A lack of effective hatching response paired with a high incidence of snake predation would select for accelerated development to reduce exposure to egg predators while keeping larvae at low risk of predation. Interestingly, we observed developmental acceleration and overall earlier spontaneous hatching in $A$. saltator and $A$. spurrelli compared to all other species, congruent with this expectation.

\section{Correlated changes in reproductive biology and clutch structure}

Why should adaptive plastic responses diverge between these closely related Agalychnis species, especially given the apparent lack of environmental differences in syntopy? One possibility is that other traits evolve that alter the intensity of selection or have pleiotropic effects on the plastic response. Agalychnis spurrelli and $A$. saltator differ from all other Agalychnis, and phyllomedusines in general, in two additional traits that might have had such an effect: breeding phenology and clutch structure.

Phyllomedusine and pelodryadine frogs are sister clades and form a monophyletic sister group to Hylinae (Faivovich et al. 2005, Wiens et al. 2005, 2006). All pelodryadine frogs, with the possible exception of Litoria longirostris, lay aquatic eggs (Richards and Alford 1992). All phyllomedusines lay eggs attached to vegetation or other structures overhanging water (Duellman 1968, Cannatella 1980, 1982, Haddad and Sawaya 2000, Duellman 2001, Neckel-Oliveira and Wachlevski 2004, Prado et al. 2005). To the best of our knowledge, other than $A$. saltator and A. spurrelli, all phyllomedusines with exposed clutches (i.e., not wrapped with leaves) lay eggs embedded in a bulky gelatinous ellipsoid (Duellman 1968, 2001, Duellman and Trueb 1986). Agalychnis saltator and A. spurrelli have a derived clutch structure (Appendix E and Fig. 5) with substantially less jelly surrounding the eggs. In contrast to other Agalychnis, females of these two species do not absorb water to hydrate the clutch before laying eggs (Savage 2002). Differences in physical structure affect the vibrational mechanics of objects (Snowdon 1968), and an equivalent force should cause lower amplitude vibrations in the flatter, stiffer $A$. spurrelli and $A$. 
saltator clutches, compared to the thicker, more gelatinous clutches of the other species. Indeed, in videotapes of snake attacks on $A$. spurrelli, much less movement and deformation of the clutch is evident, compared to similar videotapes of attacks on $A$. callidryas (I. Gomez-Mestre and K. M. Warkentin, personal observations). Because embryos use vibrations to assess danger in snake attacks (Warkentin 2005, Warkentin et al. 2006, 2007), reduced escape success might be a pleiotropic effect of a flatter clutch structure that limits vibrational information. We observed a significant interspecific association between the minimally gelatinous clutch structure and low escape hatching success under snake attacks, supporting this mechanistic hypothesis. Biomechanical properties of egg clutches could provide a partial proximate explanation for weaker responses to snakes in $A$. saltator and $A$. spurrelli, but it is nonetheless unclear why the flat clutch structure evolved, given its association with a greater vulnerability to snake predation. Additionally, a comparative analysis of vibration perception across $A g a$ lychnis is needed, because even individual $A$. spurrelli eggs (removed from their clutches) were much less responsive to mechanical disturbance than all other species studied (including $A$. saltator).

The ancestral phyllomedusine breeding phenology appears to be prolonged breeding. Pachymedusa, all thick-clutched Agalychnis, Cruziohyla, and possibly all other phyllomedusines lay eggs more or less continuously throughout the rainy season (Donnelly and Guyer 1994, Duellman 2001, Vaira 2001, Prado et al. 2005, Wogel et al. 2005). In contrast, $A$. saltator and $A$. spurrelli are explosive breeders (Scott and Starret 1974, Roberts 1994) that engage in only a few bursts of intense reproductive activity each rainy season. The change from prolonged to explosive breeding may have reduced egg predation via a predator-swamping effect (Ims 1990) in A. spurrelli and A. saltator, even if syntopic prolonged breeding species such as A. callidryas supported egg predator populations. Predator-swamping could reduce selective constraints imposed by predators on the biomechanical properties of clutches, and weaker response to snakes may have evolved as a pleiotropic effect of changes in clutch structure. Because the predator-swamping effect of explosive breeding is, in essence, a density-dependent phenomenon, it presumably functions best for large populations (Courchamp et al. 1999). Indeed, it was not evident in a small $A$. spurrelli population in Costa Rica (Gomez-Mestre and Warkentin 2007).

\section{Modular evolution of adaptive plasticity}

Adaptive phenotypic plasticity in most traits is complex, involving mechanisms for detecting environmental conditions, mechanisms for developing different phenotypes, and pathways that link environmental information to phenotype expression (Windig et al. 2004, Warkentin et al. 2007). Some of these mechanisms are fundamental parts of all development, whether monophenic or plastic, and many developmental pathways afford multiple points at which environmental sensitivity can evolve (West-Eberhard 2003, Kirschner and Gerhart 2005). Understanding the evolution of adaptive plasticity requires comparative phylogenetic analysis of the component traits that contribute to environmentally sensitive developmental pathways (e.g., perception of environmental conditions, phenotypic response). Using this approach, one can infer which traits originated or were modified under divergent selection in heterogeneous environments and which are preexisting components of development.

A mechanistic and functional framework can also generate predictions about the evolutionary lability of different components of plasticity. For instance a single cue associated with a single selective environment may trigger a single phenotypic response, resulting in a simple information pathway from environment to phenotype. Alternatively, a cue may trigger multiple phenotypic responses via diverging pathways. Similarly, a single phenotypic response may function in a single ecological context and be elicited by a single cue, or it may function in multiple contexts and be elicited by multiple cues via converging pathways.

Cases in which a single stimulus elicits a diverse array of phenotypic responses may be illustrated by plant shade responses (Smith 2000). The ratio of red to far-red light detected by phytochromes cues multiple phenotypic responses to the risk of shading by competitors (Schmitt et al. 1999, Dorn et al. 2000, Smith 2000, Sullivan and Deng 2003). In this case, individual phenotypic responses (e.g., stem elongation, suppression of branching, accelerated flowering) appear relatively evolutionarily labile (Pigliucci et al. 1999, Botto and Smith 2002), evolving even among populations within species (Donohue et al. 2001). In contrast, the cue detection mechanism (i.e., the photosensory function of phytochrome) is highly conserved, from cyanobacteria through angiosperms (Montgomery and Lagarias 2002). Indeed the photosensory domain of phytochrome is evolving much more slowly than its regulatory domain (Alba et al. 2000).

Plastic shifts in the timing of ontogenetic switch points exemplify cases in which a single response functions in multiple contexts (e.g., in response to predators, pathogens, abiotic stressors). In such multifunctional responses a variety of cue detection mechanisms must lead into a single pathway, resulting in a phenotypic response. For instance, plastic acceleration of metamorphosis occurs in response to various environmental factors (e.g., pond drying, predators, competition) and is mediated, at least in part, by a generalized stress response (Denver 1997a, b). Any of those risks could initially select for switch point plasticity. Then, once the initial plasticity has evolved, it might be relatively easy to evolve a response to additional cues, utilizing preexisting components of the 
pathway. Thus, the capacity to switch life stages at different ages, sizes, or developmental stages may be older and more widespread than its expression in response to any particular selective factor or cue. Similarly, when the same plastic response serves multiple functions, any one of those functions may be sufficient to maintain the plasticity through periods of relaxed selection by other factors. This would make the capacity to express different phenotypes less evolutionarily labile (specifically, less likely to be lost) than the response to any individual factor or cue. Our results on hatching plasticity in treefrogs are congruent with this scenario of a single plastic response with multiple cues and functions in which the response to specific cues is evolutionarily more labile than the overall capacity for plasticity.

Different components of the pathways leading to adaptive plastic responses may have different evolutionary histories. The evolutionary lability of these components will vary with selective factors acting on them in multiple contexts, depending on the number of information pathways to which they contribute, as well as with constraints imposed by the developmental mechanisms in which they participate. Thus, to understand how plasticity evolves will require comparative studies reconstructing the evolution of different components of plasticity and consideration of both the mechanistic role of these components and their contribution in multiple ecological contexts.

\section{ACKNOWLEDGMENTS}

We thank M. Solano and J. Pinto for their assistance and guidance in the field in Costa Rica, and A. Chavez, O. de Miguel Campanero, M. Barrios, and C. Chagoyan in Mexico. In Costa Rica, B. Kubicki, E. Berlin, and H. Hoffman granted permission and facilitated access to their lands and frog populations therein. J. Hernandez and staff at Fundación Zoológico Simón Bolivar (San Jose, Costa Rica) provided logistical support for work with Agalychnis annae within the zoological park. In Guatemala, H. Fuentes and D. Guerra helped in finding $A$. moreletii and hosted the experimental work within the Hospital Veterinario at Universidad San Carlos. F. Bolaños, T. Contreras, J. Malone, and L. Briseño gave helpful advice and population locality information. J. Alvarado kindly lent us two captive Leptodeira maculata for experiments on $P$. dacnicolor. We thank EARTH University and La Selva Biological Station (OTS) for logistical support. C. J. Schneider kindly allowed I. Gomez-Mestre to conduct part of the molecular work in his laboratory, and B. Estrada, S. A. Smith, P. Stephens, C. Kieswetter, and M. Meegaskumbura shared protocols or otherwise helped in obtaining the molecular data. This research was conducted under permits from the Ministerio del Ambiente y Energía of Costa Rica, Consejo Nacional de Áreas Protegidas (CONAP) of Guatemala, and Secretaría de Medio Ambiente y Recursos Naturales (SEMARNAT) of Mexico. It was funded by the National Geographic Society (7541-03), Ministerio de Educación y Ciencia, Spain (\#EX20020640), National Science Foundation (IBN-0234439; EF 0334923), and Boston University.

\section{Literature Cited}

Ackerly, D. D., and M. J. Donoghue. 1998. Leaf size, sapling allometry, and Corner's rules: phylogeny and correlated evolution in maples (Acer). American Naturalist 152:767791.
Ackerly, D. D., and P. B. Reich. 1999. Convergence and correlations among leaf size and function in seed plants: a comparative test using independent contrasts. American Journal of Botany 86:1272-1281.

Alba, R., P. M. Kelmenson, M. M. Cordonnier-Pratt, and L. H. Pratt. 2000. The phytochrome gene family in tomato and the rapid differential evolution of this family in angiosperms. Molecular Biology and Evolution 17:362-373.

Alfaro, M. E., S. Zoller, and F. Lutzoni. 2003. Bayes or bootstrap? A simulation study comparing the performance of Bayesian Markov chain Monte Carlo sampling and bootstrapping in assessing phylogenetic confidence. Molecular Biology and Evolution 20:255-266.

Allison, P. D. 1995. Survival analysis using the SAS system: a practical guide. SAS Institute, Cary, North Carolina, USA.

Archie, J. W. 1996. Measures of homoplasy. Pages 153-188 in M. J. Sanderson and L. Hufford, editors. Homoplasy: the recurrence of similarity in evolution. Academic Press, San Diego, California, USA.

Arnold, S. J. 1986. Limits on stabilizing, disruptive, and correlational selection set by the opportunity for selection. American Naturalist 128:143-146.

Bell, D. L., and S. E. Sultan. 1999. Dynamic phenotypic plasticity for root growth in Polygonum: a comparative study. American Journal of Botany 86:807-819.

Benard, M. F. 2004. Predator-induced phenotypic plasticity in organisms with complex life histories. Annual Review of Ecology and Systematics 35:651-673.

Botto, J. F., and H. Smith. 2002. Differential genetic variation in adaptive strategies to a common environmental signal in Arabidopsis accessions: phytochrome-mediated shade avoidance. Plant Cell and Environment 25:53-63.

Bradford, D. F., and R. S. Seymour. 1988. Influence of water potential on growth and survival of the embryo, and gas conductance of the egg, in a terrestrial breeding frog, Pseudophryne bibroni. Physiological Zoology 61:470-474.

Brandley, M. C., A. Schmitz, and T. W. Reeder. 2005. Partitioned Bayesian analyses, partition choice, and the phylogenetic relationships of scincid lizards. Systematic Biology 54:373-390.

Burnham, K. P., and D. R. Anderson. 2002. Model selection and multi-model inference: a practical information-theoretic approach. Springer-Verlag, New York, New York, USA.

Bussing, W. A. 2002. Freshwater fishes of Costa Rica. Second edition. Universidad de San Jose, San Jose, Costa Rica.

Cannatella, D. C. 1980. A review of the Phyllomedusa buckleyi group (Anura: Hylidae). Occasional Papers of the Museum of Natural History, The University of Kansas 87:1-40.

Cannatella, D. C. 1982. Leaf-frogs of the Phyllomedusa perinesos group (Anura: Hylidae). Copeia 1982:501-513.

Chivers, D. P., J. M. Kiesecker, A. Marco, J. De Vito, M. T. Anderson, and A. R. Blaustein. 2001. Predator-induced life history changes in amphibians: egg predation induces hatching. Oikos 92:135-142.

Colbourne, J. K., P. D. N. Hebert, and D. J. Taylor. 1997. Evolutionary origins of phenotypic diversity in Daphnia. Pages 163-188 in T. J. Givnish and K. J. Sytsma, editors. Molecular evolution and adaptive radiation. Cambridge University Press, Cambridge, UK.

Courchamp, F., T. Clutton-Brock, and B. Grenfell. 1999. Inverse density dependence and the Allee effect. Trends in Ecology and Evolution 14:405-410.

Crawley, M. J. 1993. GLIM for ecologists. Blackwell Science, Oxford, UK.

Cruz, C. A. G. d. 1990. Sobre as relaçoes intergenericas de Phyllomedusinae da Floresta Atlantica (Amphibia, Anura, Hylidae). Revista Brasileira de Biologia 50:709-726.

Czerkies, P., P. Brzuzan, K. Kordalski, and M. Luczynski. 2001. Critical partial pressures of oxygen causing precocious hatching in Coregonus lavaretus and C. albula embryos. Aquaculture 196:151-158. 
Denver, R. J. 1997a. Environmental stress as a developmental cue: corticotropin-releasing hormone is a proximate mediator of adaptive phenotypic plasticity in amphibian metamorphosis. Hormones and Behavior 31:169-179.

Denver, R. J. 1997b. Proximate mechanisms of phenotypic plasticity in amphibian metamorphosis. American Zoologist 37:172-184.

DeWitt, T. J., and S. M. Scheiner. 2004. Phenotypic plasticity: functional and conceptual approaches. Oxford University Press, Oxford, UK.

DiMichele, L., and M. H. Taylor. 1980. The environmental control of of hatching in Fundulus heteroclitus. Journal of Experimental Zoology 214:181-187.

Donnelly, M. A., and C. Guyer. 1994. Patterns of reproduction and habitat use in an assemblage of Neotropical hylid frogs. Oecologia 98:291-302.

Donohue, K., E. H. Pyle, D. Messiqua, M. S. Heschel, and J. Schmitt. 2001. Adaptive divergence in plasticity in natural populations of Impatiens capensis and its consequences for performance in novel habitats. Evolution 55:692-702.

Dorn, L. A., E. Hammond Pyle, and J. Schmitt. 2000. Plasticity to light cues and resources in Arabidopsis thaliana: testing for adaptive value and costs. Evolution 54:1982-1994.

Doughty, P. 1995. Testing the ecological correlates of phenotypically plastic traits within a phylogenetic framework. Acta Oecologica 16:519-524.

Duellman, W. E. 1958. A monographic study of the colubrid snake genus Leptodeira. Bulletin of the American Museum of Natural History 114:1-152.

Duellman, W. E. 1968. The genera of phyllomedusine frogs (Anura: Hylidae). University of Kansas Publications, Museum of Natural History 18:1-10.

Duellman, W. E. 2001. The hylid frogs of Middle America. Second edition. Society for the Study of Amphibians and Reptiles, Ithaca, New York, USA.

Duellman, W. E., and L. Trueb. 1986. Biology of amphibians. McGraw-Hill, New York, New York, USA.

Faivovich, J., C. F. B. Haddad, P. C. A. Garcia, D. R. Frost, J. A. Campbell, and W. C. Wheeler. 2005. Systematic review of the frog family Hylidae, with special reference to Hylinae: phylogenetic analysis and taxonomic revision. Bulletin of the American Museum of Natural History 294:1-240.

Fallis, S. P., and K. R. Snow. 1983. The hatching stimulus for eggs of Aedes punctor (Diptera, Culicidae). Ecological Entomology 8:23-28.

Felsenstein, J. 1985a. Confidence limits on phylogenies: an approach using the bootstrap. Evolution 39:783-791.

Felsenstein, J. 1985b. Phylogenies and the comparative method. American Naturalist 125:1-15.

Garcia, L. V. 2003. Controlling the false discovery rate in ecological research. Trends in Ecology and Evolution 18:553554.

Gjullin, C. M., C. P. Hegarty, and W. B. Bollen. 1941. The necessity of a low oxygen concentration for the hatching of Aedes mosquito eggs. Journal of Cellular and Comparative Physiology 17:193-202.

Gomez-Mestre, I., and D. R. Buchholz. 2006. Developmental plasticity mirrors differences among taxa in spadefoot toads linking plasticity and diversity. Proceedings of the National Academy of Sciences (USA) 103:19021-19026.

Gomez-Mestre, I., J. C. Touchon, and K. M. Warkentin. 2006. Amphibian embryo and parental defenses and a larval predator reduce egg mortality from water mold. Ecology 87:2570-2581.

Gomez-Mestre, I., and K. Warkentin. 2007. To hatch and hatch not: similar selective trade-offs but different responses to egg predators in two closely related, syntopic treefrogs. Oecologia 153:197-206.

Gosner, K. L. 1960. A simplified table for staging anuran embryos and larvae with notes on identification. Herpetologica 16:183-190.
Gosselin, L. A., and P.-Y. Qian. 1997. Juvenile mortality in benthic marine invertebrates. Marine Ecology Progress Series 146:265-282.

Gotthard, K., and S. Nylin. 1995. Adaptive plasticity and plasticity as an adaptation: a selective review of plasticity in animal morphology and life history. Oikos 74:3-17.

Haddad, C. F. B., and R. J. Sawaya. 2000. Reproductive modes of Atlantic forest hylid frogs: a general overview and the description of a new mode. Biotropica 32:862-871.

Hall, B. K., and M. H. Wake. 1999. Larval development, evolution, and ecology. Pages 1-19 in B. K. Hall and M. H. Wake, editors. The origin and evolution of larval forms. Academic Press, San Diego, California, USA.

Hillis, D. M., and J. J. Bull. 1993. An empirical test of bootstrapping as a method for assessing confidence in phylogenetic analysis. Systematic Biology 42:182-192.

Huelsenbeck, J. P., and B. Rannala. 2004. Frequentist properties of Bayesian posterior probabilities of phylogenetic trees under simple and complex substitution models. Systematic Biology 53:904-913.

Huelsenbeck, J. P., and F. Ronquist. 2001. MRBAYES: Bayesian inference of phylogenetic trees. Bioinformatics 17: $754-755$.

Ims, R. A. 1990. On the adaptive value of reproductive synchrony as a predator-swamping strategy. American Naturalist 136:485-498.

Ireland, D., A. Wirsing, and D. Murray. 2007. Phenotypically plastic responses of green frog embryos to conflicting predation risk. Oecologia 152:162-168.

Kembel, S. W., and J. F. Cahill. 2005. Plant phenotypic plasticity belowground: a phylogenetic perspective on root foraging trade-offs. American Naturalist 166:216-230.

Kirschner, M. W., and J. C. Gerhart. 2005. The plausibility of life. Yale University Press, New Haven, Connecticut, USA.

Kubicki, B. 2004. Leaf frogs of Costa Rica. INBio, San Jose, Costa Rica.

Kusch, R. C., and D. P. Chivers. 2004. The effects of crayfish predation on phenotypic and life-history variation in fathead minnows. Canadian Journal of Zoology 82:917-921.

Latham, K. E., and J. J. Just. 1989. Oxygen availability provides a signal for hatching in the rainbow trout (Salmo gairdneri) embryo. Canadian Journal of Fisheries and Aquatic Sciences 46:55-58.

Laurila, A., S. Pakkasmaa, P. A. Crochet, and J. Merila. 2002. Predator-induced plasticity in early life history and morphology in two anuran amphibians. Oecologia 132:524-530.

Lee, H. S., A. R. Zangerl, K. Garbutt, and F. A. Bazzaz. 1986. Within and between species variation in response to environmental gradients in Polygonum pensylvanicum and Polygonum virginianum. Oecologia 68:606-610.

Lee, J. C. 2000. Amphibians and reptiles of the Maya world. Cornell University Press, Ithaca, New York, USA.

Leips, J., and J. Travis. 1994. Metamorphic responses to changing food levels in two species of hylid frogs. Ecology 75: 1345-1356.

Losos, J. B., T. W. Schoener, and D. A. Spiller. 2003. Effect of immersion in seawater on egg survival in the lizard Anolis sagrei. Oecologia 137:360-362.

Maddison, W. P., and D. R. Maddison. 2006. Mesquite: a modular system for evolutionary analysis. 〈http:// mesquiteproject.org

Martin, K. L. M. 1999. Ready and waiting: delayed hatching and extended incubation of anamniotic vertebrate terrestrial eggs. American Zoologist 39:279-288.

Martins, E. P. 1999. Estimation of ancestral states of continuous characters: a computer simulation study. Systematic Biology 48:642-650.

Martins, E. P. 2004. Compare. Version 4.6b. Computer programs for the statistical analysis of comparative data. $\langle$ http://compare.bio.indiana.edu $\rangle$ 
Martins, E. P., and T. F. Hansen. 1997. Phylogenies and the comparative method: a general approach to incorporating phylogenetic information into analysis of interspecific data. American Naturalist 149:646-667.

Miller, P. L. 1992. The effect of oxygen lack on egg hatching in an Indian dragonfly, Potamarcha congener. Physiological Entomology 17:68-72.

Montgomery, B. L., and J. C. Lagarias. 2002. Phytochrome ancestry: sensors of bilins and light. Trends in Plant Science 7:357-366.

Moreira, P. L., and M. Barata. 2005. Egg mortality and early embryo hatching caused by fungal infection of Iberian rock lizard (Lacerta monticola) clutches. Herpetological Journal 15:265-272.

Morey, S. R., and D. Reznick. 2000. A comparative analysis of plasticity in larval development in three species of spadefoot toads. Ecology 81:1736-1749.

Morey, S. R., and D. N. Reznick. 2004. The relationship between habitat permanence and larval development in California spadefoot toads: field and laboratory comparisons of developmental plasticity. Oikos 104:172-190.

Neckel-Oliveira, S., and M. Wachlevski. 2004. Predation on the arboreal eggs of three species of Phyllomedusa in Central Amazonia. Journal of Herpetology 38:244-248.

Newman, R. A. 1992. Adaptive plasticity in amphibian metamorphosis. BioScience 42:671-678.

Nylander, J. A. A. 2004. MrModeltest 2.0. Evolutionary Biology Centre, Uppsala University, Uppsala, Sweden.

Nylander, J. A. A., F. Ronquist, J. P. Huelsenbeck, and J. L. Nieves-Aldrey. 2004. Bayesian phylogenetic analysis of combined data. Systematic Biology 53:47-67.

Pagel, M. 1999. The maximum likelihood approach to reconstructing ancestral character states of discrete characters on phylogenies. Systematic Biology 48:612-622.

Petranka, J. W., J. J. Just, and E. C. Crawford. 1982. Hatching of amphibian embyos: the physiological trigger. Science 217: 257-259.

Pigliucci, M. 2001. Phenotypic plasticity: beyond nature and nurture. Johns Hopkins University Press, Baltimore, Maryland, USA.

Pigliucci, M., K. Cammell, and J. Schmitt. 1999. Evolution of phenotypic plasticity: a comparative approach in the phylogenetic neighbourhood of Arabidopsis thaliana. Journal of Evolutionary Biology 12:779-791.

Prado, C. P. A., M. Uetanabaro, and C. F. B. Haddad. 2005. Breeding activity patterns, reproductive modes, and habitat use by anurans (Amphibia) in a seasonal environment in the Pantanal, Brazil. Amphibia-Reptilia 26:211-221.

Pyburn, W. F. 1963. Observations on the life history of the treefrog, Phyllomedusa callidryas (Cope). Texas Journal of Science 15:155-170.

Pyburn, W. F. 1970. Breeding behavior of the leaf-frogs Phyllomedusa callidryas and Phyllomedusa dacnicolor in Mexico. Copeia 1970:209-218.

Richards, S. J., and R. A. Alford. 1992. Nest construction by an Australian rainforest frog of the Litoria lesueuri complex (Anura: Hylidae). Copeia 1992:1120-1123.

Roberts, W. E. 1994. Explosive breeding aggregations and parachuting in a neotropical frog, Agalychnis saltator (Hylidae). Journal of Herpetology 28:193-199.

Roskam, J. C., and P. M. Brakefield. 1996. A comparison of temperature-induced polyphenism in African Bicyclus butterflies from a seasonal savannah-rainforest ecotone. Evolution 50:2360-2372.

Rowe, L., and D. Ludwig. 1991. Size and timing of metamorphosis in complex life cycles: time constraints and variation. Ecology 72:413-427.

Saenz, D., J. B. Johnson, C. K. Adams, and G. H. Dayton. 2003. Accelerated hatching of southern leopard frog (Rana sphenocephala) eggs in response to the presence of a crayfish (Procambarus nigrocinctus) predator. Copeia 2003:646-649.
SAS Institute. 2003. SAS/STAT 9.1 software. SAS Institute, Cary, North Carolina, USA.

Savage, J. M. 2002. The amphibians and reptiles of Costa Rica. University of Chicago Press, Chicago, Illinois, USA.

Schmidt, B. R., and J. Van Buskirk. 2005. A comparative analysis of predator-induced plasticity in larval Triturus newts. Journal of Evolutionary Biology 18:415-425.

Schmitt, J., S. A. Dudley, and M. Pigliucci. 1999. Manipulative approaches to testing adaptive plasticity: phytochromemediated shade-avoidance responses in plants. American Naturalist 154:S43-S54.

Schwilk, D. W. 2001. Cactus 1.13. Comparative analysis of continuous traits using statistics. Prickly Software. 〈http:// www.pricklysoft.org/software/cactus.html $\rangle$

Schwilk, D. W., and D. D. Ackerly. 2001. Flammability and serotiny as strategies: correlated evolution in pines. Oikos 94: 326-336.

Scott, N. J., and A. Starret. 1974. An unusual breeding aggregation of frogs, with notes on the ecology of Agalychnis spurrelli (Anura: Hylidae). Bulletin of the Southern California Academy of Sciences 73:86-94.

Seymour, R. S., J. D. Roberts, N. J. Mitchell, and A. J. Blaylock. 2000. Influence of environmental oxygen on development and hatching of aquatic eggs of the Australian frog, Crinia geogiana. Physiological and Biochemical Zoology 73:501-507.

Sih, A., and R. D. Moore. 1993. Delayed hatching of salamander eggs in response to enhanced larval predation risk. American Naturalist 142:947-960.

Smith, H. 2000. Phytochromes and light signal perception by plants: an emerging synthesis. Nature 407:585-591.

Snowdon, J. C. 1968. Vibration and shock in damped mechanical systems. John Wiley and Sons, Hoboken, New Jersey, USA.

Stearns, S. 1989. The evolutionary significance of phenotypic plasticity. BioScience 39:436-445.

Stoks, R., M. A. McPeek, and J. L. Mitchell. 2003. Evolution of prey behavior in response to changes in predation regime: damselflies in fish and dragonfly lakes. Evolution 57:574-585.

Sullivan, J. A., and X. W. Deng. 2003. From seed to seed: the role of photoreceptors in Arabidopsis development. Developmental Biology 260:289-297.

Swofford, D. L. 2002. PAUP: phylogenetic analysis using parsimony. Version 4.0b10. Sinauer, Sunderland, Massachusetts, USA.

Thompson, J. D., D. G. Higgins, and T. J. Gibson. 1994. Clustal-W: improving the sensitivity of progressive multiple sequence alignment through sequence weighting, positionspecific gap penalties and weight matrix choice. Nucleic Acids Research 22:4673-4680.

Tollrian, R., and C. D. Harvell. 1998. The ecology and evolution of inducible defenses. Princeton University Press, Princeton, New Jersey, USA.

Vaira, M. 2001. Breeding biology of the leaf frog, Phyllomedusa boliviana (Anura, Hylidae). Amphibia-Reptilia 22:421-429.

Van Buskirk, J. 2002. A comparative test of the adaptive plasticity hypothesis: relationships between habitat and phenotype in anuran larvae. American Naturalist 160:87102.

Van Gool, E., and J. Ringelberg. 1998. Light-induced migration behaviour of Daphnia modified by food and predator kairomones. Animal Behaviour 56:741-747.

Verhoeven, K. J. F., K. L. Simonsen, and L. M. McIntyre. 2005. Implementing false discovery rate control: increasing your power. Oikos 108:643-647.

Vonesh, J. R. 2005. Egg predation and predator-induced hatching plasticity in the African reed frog, Hyperolius spinigularis. Oikos 110:241-252.

Warkentin, K. M. 1995. Adaptive plasticity in hatching age: a response to predation risk trade-offs. Proceedings of the National Academy of Sciences (USA) 92:3507-3510. 
Warkentin, K. M. 1999. Effects of hatching age on development and hatchling morphology in the red-eyed treefrog, Agalychnis callidryas. Biological Journal of the Linnean Society 68 : 443-470.

Warkentin, K. M. 2000a. Environmental and developmental effects on external gill loss in the red-eyed tree frog, Agalychnis callidryas. Physiological and Biochemical Zoology 73:557-565.

Warkentin, K. M. 2000b. Wasp predation and wasp-induced hatching of red-eyed treefrog eggs. Animal Behaviour 60: 503-510.

Warkentin, K. M. 2002. Hatching timing, oxygen availability, and external gill regression in the tree frog, Agalychnis callidryas. Physiological and Biochemical Zoology 75:155164.

Warkentin, K. M. 2005. How do embryos assess risk? Vibrational cues in predator-induced hatching of red-eyed treefrogs. Animal Behaviour 70:59-71.

Warkentin, K. M. 2007. Oxygen, gills, and embryo behavior: mechanisms of adaptive plasticity in hatching. Comparative Biochemistry and Physiology A: Molecular and Integrative Physiology 148:720-731.

Warkentin, K. M., M. S. Caldwell, and J. G. McDaniel. 2006. Temporal pattern cues in vibrational risk assessment by embryos of the red-eyed treefrog, Agalychnis callidryas. Journal of Experimental Biology 209:1376-1384.

Warkentin, K. M., M. S. Caldwell, T. D. Siok, A. T. D'Amato, and J. G. McDaniel. 2007. Flexible information sampling in vibrational risk assessment by red-eyed treefrog embryos. Journal of Experimental Biology 210:614-619.

Warkentin, K. M., C. R. Currie, and S. A. Rehner. 2001. Eggkilling fungus induces early hatching of red-eyed treefrog eggs. Ecology 82:2860-2869.

Webb, C. O., D. D. Ackerly, and S. W. Kembel. 2006. Phylocom: software for the analysis of community phylogenetic structure and trait evolution. 〈http://www. phylodiversity.net/phylocom/ $>$

Wedekind, C. 2002. Induced hatching to avoid infectious egg disease in whitefish. Current Biology 12:69-71.
Werner, E. E. 1986. Amphibian metamorphosis: growth rate, predation risk, and the optimal size at transformation. American Naturalist 128:319-341.

Werner, E. E. 1988. Size, scaling, and the evolution of complex life cycles. Pages $60-81$ in B. Ebenman and L. Persson, editors. Size-structured populations. Springer-Verlag, Berlin, Germany.

Werner, E. E., and J. F. Gilliam. 1984. The ontogenetic niche and species interactions in size-structured populations. Annual Review of Ecology and Systematics 15:393-425.

West-Eberhard, M. J. 2003. Developmental plasticity and evolution. Oxford University Press, Oxford, UK.

Wiens, J. J. 1998. Combining data sets with different phylogenetic histories. Systematic Biology 47:568-581.

Wiens, J. J., J. W. Fetzner, C. L. Parkinson, and T. W. Reeder. 2005. Hylid frog phylogeny and sampling strategies for speciose clades. Systematic Biology 54:719-748.

Wiens, J. J., C. H. Graham, D. S. Moen, S. A. Smith, and T. W. Reeder. 2006. Evolutionary and ecological causes of the latitudinal diversity gradient in hylid frogs: treefrog trees unearth the roots of high tropical diversity. American Naturalist 168:579-596.

Wilbur, H. M. 1980. Complex life cycles. Annual Review of Ecology and Systematics 11:67-93.

Wilbur, H. M., and J. P. Collins. 1973. Ecological aspects of amphibian metamorphosis. Science 182:1305-1314.

Wilcox, T. P., D. J. Zwickl, T. A. Heath, and D. M. Hillis. 2002. Phylogenetic relationships of the dwarf boas and a comparison of Bayesian and bootstrap measures of phylogenetic support. Molecular Phylogenetics and Evolution 25: 361-371.

Windig, J. J., C. G. F. De Kovel, and G. De Jong. 2004. Genetics and mechanics of plasticity. Pages 31-49 in T. J. DeWitt and S. M. Scheiner, editors. Phenotypic plasticity. Oxford University Press, Oxford, UK.

Wogel, H., P. A. Abrunhosa, and J. P. Pombal. 2005. Breeding behaviour and mating success of Phyllomedusa rohdei (Anura, Hylidae) in south-eastern Brazil. Journal of Natural History 39:2035-2045.

APPENDIX A

A brief description of the species studied, natural history, and study localities (Ecological Archives M078-007-A1).

\section{APPENDIX B}

A list of specimens used in molecular analyses (Ecological Archives M078-007-A2).

\section{APPENDIX C}

A list of primers used in the study for polymerase chain reaction amplification and sequencing of three mitochondrial and four nuclear loci (Ecological Archives M078-007-A3).

\section{APPENDIX D}

GenBank accession numbers for DNA sequences analyzed in this study (Ecological Archives M078-007-A4).

\section{APPENDIX E}

Examples of egg clutches of phyllomedusine hylid frogs, Agalychnis and Pachymedusa, showing differences between highly gelatinous and minimally gelatinous clutches (Ecological Archives M078-007-A5).

\section{APPENDIX F}

Differences in size and developmental stage between early induced hatchlings and modal spontaneous hatchlings in six phyllomedusine treefrogs (Agalychnis and Pachymedusa) (Ecological Archives M078-007-A6). 